\title{
¿REPRIMARIZACIÓN EN LA PERIFERIA?: EL CASO BRASILEÑO (2003-2013)
}

\section{REPRIMARIZATION IN THE PERIPHERY? THE BRAZILIAN CASE (2003-2013)}

\author{
CHRISTIAN OROZCO \\ Universidad Complutense de Madrid \\ croschris@hotmail.com
}

Fecha de recepción: noviembre 2016

Fecha de aceptación: diciembre 2016

\section{RESUMEN}

El propósito de esta investigación es adentrarnos en la discusión sobre el significado de la desindustrialización, entendiendo que este fenómeno se puede manifestar de distintas formas dependiendo de dos factores: el primero, relacionado con el grado de desarrollo general e industrial de una economía; y el segundo, asociado a la abundancia/dependencia de uno o una pequeña cesta de productos primarios. Por otra parte, asumiendo que la economía brasileña lleva experimentando un proceso de desindustrialización dependiente desde finales de los años ochenta y, sobre todo, mediados de los noventa; nos centramos en constatar si en el periodo comprendido entre 2003 y 2013 se ha producido un proceso de reprimarización, interpretando este fenómeno como una vertiente de la llamada enfermedad holandesa. La metodología empírica aplicada está basada en el análisis de datos organizados en tablas y figuras. La conclusión principal, anticipada aquí, es que hay pocos indicios que apuntan a que Brasil ha experimentado durante el periodo de estudio un proceso de reprimarización de su estructura productiva.

PALABRAS CLAVE: enfermedad holandesa, desarrollo dependiente, estructura productiva, desindustrialización, reprimarización.

\begin{abstract}
The purpose of this research is to get into the discussion about the meaning of deindustrialization, understanding that this phenomenon can manifest itself in different ways depending on two factors: the first related to the level of general and industrial development in an economy; and second, associated with the abundance / dependence on one or a small basket of commodities. Moreover, assuming that the Brazilian economy has been undergoing a process of dependent industrialization since the late eighties and, above all, the mid-nineties; we focus on finding if in the period between 2003 and 2013 there has been a process of reprimarization, interpreting this phenomenon as a branch of the so-called Dutch disease. The empirical methodology is based on analysis of data organized in tables and figures. The main conclusion, anticipated here, is that there is little evidence that Brazil has experienced during the period of study a process of reprimarization of its productive structure.
\end{abstract}


Orozco, Christian. ¿Reprimarización en la periferia?: El caso brasileño (2003-2013).

KEY WORDS: Dutch disease, dependent development, productive structure, deindustrialization, reprimarization.

JEL: E23, F14, L6, L7, O14, O54, Q34.

\section{INTRODUCCIÓN}

Entre 1930 y 1980, Brasil experimentó un proceso rápido y acelerado de industrialización en un contexto de aplicación de políticas denominadas desarrollistas, un periodo marcado por altas tasas de crecimiento económico con la incorporación de sectores industriales modernos, la consolidación de las cadenas de suministros y la integración del mercado nacional, bajo la hegemonía de Sao Paulo. No obstante, desde mediados de la década de los ochenta, en un contexto de crisis fiscal y financiera del Estado, los datos oficiales de la Contabilidad Nacional de Brasil empezaron a señalar un cambio en la estructura de la oferta agregada, tanto los distintos sectores industriales del país como la tasa de crecimiento del PIB empezaron a deprimirse ostensiblemente.

A esta situación, que varios investigadores estructuralistas han definido como una industrialización "trunca" o una desindustrialización "precoz" hay que añadir, a principios del siglo XXI, una serie de factores como el importante crecimiento de la demanda y el precio internacional de las commodities; la acentuación del carácter dependiente de la economía no solo en relación a los países centrales sino también en relación con otras economías no desarrolladas como China; o los descubrimiento de petróleo en el Presal, nos conducen a pensar en la posibilidad de que Brasil esté experimentando un proceso de reprimarización de su economía, por el cual, el proceso de desindustrialización que experimentó a partir de los años ochenta se profundiza aún más en el presente siglo.

En este contexto, el objetivo del presente estudio es evidenciar empíricamente si, de hecho, la economía brasileña está experimentando un proceso de reprimarización de su estructura productiva y su inserción exterior entre 2003 y 2013 . Mientras que los objetivos específicos son los siguientes:

i) sintetizar y entender la forma en como las distintas escuelas de pensamiento económico conceptualizan el fenómeno de la desindustrialización;

ii) analizar los procesos de industrialización y desindustrialización brasileños a partir de un enfoque histórico-estructural, como una condición ineludible para poder abordar consecuentemente la pregunta de esta investigación.

Para ello, el presente estudio se divide en tres secciones, además de la introducción y las conclusiones. En un primer momento, se describen sucintamente los debates que desde distintas escuelas y corrientes han surgido en torno a la conceptualización del proceso de desindustrialización, distinguiendo, por una parte, las especificidades del proceso en economías centrales y periféricas-dependientes, y, por otra parte, cuando este fenómeno está más asociado a la tercerización de la economía y cuando se vincula más a la conocida como enfermedad holandesa y reprimarización. En segundo lugar, apuntamos una serie de características estructurales e históricas de la economía brasileña, para concluir que tanto su proceso industrializador como su posterior desindustrialización cuentan con marcados rasgos de dependencia y debilidad estructural. Y, por último, a través del análisis sistemático de la evolución de una serie de indicadores de la economía 
Orozco, Christian. ¿Reprimarización en la periferia?: El caso brasileño (2003-2013).

brasileña comprobaremos si es preciso hablar 0 no de un proceso de reprimarización de la economía del país sudamericano.

Los resultados presentados en esta investigación buscan aportar una mejor compresión de los procesos de merma del sector industrial en economías periféricas-dependientes, particularmente en aquellas economías que presentan un notable sector vinculado a las commodities.

\section{DEBATE TEÓRICO}

\subsection{El proceso de desindustrialización: economías centrales y periféricas- dependientes}

Desde los enfoques dominantes en los estudios de la economía del desarrollo, el fenómeno de la desindustrialización se conceptualiza como una evolución natural que experimentan las economías más avanzadas hacia sectores terciarios. Así pues, las economías desarrolladas a partir de los años setenta estarían transitando hacia sociedades postindustriales, sociedades basadas en los servicios. En esta línea, Cohen y Zysman (1987) recogen en su obra interesantes aportaciones que en el marco de la economía estadounidense de la década de los ochenta se planteaban abiertamente desde la esfera política e ideológica. En 1983, la revista Forbes se manifestaba favorable a esta tesis:

"En lugar de alertar sobre la disminución de nuestro poder económico, una economía impulsada por los servicios da señales de que nos encontramos en la etapa más avanzadas del desarrollo económico... En lugar de seguir al flautista de Hamelín de la reindustrialización, Ios EE.UU. deben concentrar sus esfuerzos en el fortalecimiento de sus servicios ${ }^{1 "}$ (Forbes, 1983).

Así pues, desde los años ochenta se va consolidando una visión evolucionista de la economía basada en fases o estadios consecutivos. La primera etapa es la agricultura, la industria es la segunda, y los servicios -especialmente los basados en altos niveles de cualificación- es la tercera, y de momento la última etapa (Cohen y Zysman, 1988: 5).

A finales de los años noventa, el FMI presenta dos estudios en los que los investigadores Rowthorn y Ramaswamy profundizan sobre esta visión del fenómeno. En cuanto a las aportaciones de sendos informes cabe resaltar: primero, emplean el concepto de desindustrialización para referirse a la "caída secular de la participación del empleo industrial en las economías avanzadas". Segundo, asumen que este fenómeno no es per se negativo (Rowthorn y Ramaswamy, 1998: 4), y argumentan que el aumento en los niveles de desigualdad y de desempleo son anteriores al mismo. En tercer lugar, los autores sí consideran la posibilidad de que el proceso de desindustrialización esté relacionado con problemas en el sector industrial o en la economía en su conjunto, sin embargo, plantean que estos caso son minoritarios, y además, causados por shocks externos que provocan que todo el empleo perdido en la industria no sea absorbido por los puestos de trabajo generados en los servicios, desembocando, por tanto, en mayores tasas de desempleo y menores niveles de vida para la población (Rowthorn y Ramaswamy, 1997: 14).

\footnotetext{
${ }^{1}$ Traducción propia.

Papeles de Europa 
Orozco, Christian. ¿Reprimarización en la periferia?: El caso brasileño (2003-2013).

Desde esta perspectiva los procesos de desindustrialización estarían basados principalmente en la existencia de crecientes divergencias productivas entre el sector secundario y el terciario, mientras que las manufacturas son actividades "tecnológicamente progresivas", los servicios están, por el contrario, "tecnológicamente estancados"2 (Rowthorn y Ramaswamy, 1997: 21). Así pues, Baumol (1966, 1967), predice un aumento del crecimiento relativo del nivel de empleo en el sector terciario como resultado de esta divergencia productiva, un incremento relativo del sector industrial y un aumento de los precios relativos de los servicios. Lógicamente, a partir de estas inferencias se puede explicar tanto la caída del número de empresas industriales como la reducción del empleo generado por la industria manufacturera (Grigera, 2011: 88; Silva, 2014). Rowthorn y Ramaswamy, autores pioneros en la recuperación de las tesis de Baumol, estiman que dos terceras partes de los datos sobre desindustrialización ${ }^{3}$ de las economías industrializadas pueden explicarse por este diferencial de productividad, mientras que el tercio restante está relacionado con modificaciones en los patrones de consumo ${ }^{4}$ (Pasinetti, 1981), alteraciones en las estructuras de exportaciones, y cambios estrictamente contables ${ }^{5}$ (Grigera, 2011: 89).

Así pues, mientras los autores liberales y neoliberales caracterizan y explican la desindustrialización fundamentalmente como un proceso interno intrínseco al propio desarrollo de las economías avanzadas, gran parte de los autores más cercanos al enfoque keynesiano (neokeynesianos principalmente), compartiendo esta primera explicación, señalan, además, que existen factores internacionales que desempeñan un papel relevante en el proceso de desindustrialización. Así pues, la deslocalización y la subcontratación internacional entre países industrializados y economías emergentes, asociadas a una etapa de exacerbación en los volúmenes de internacionalización del capital, han supuesto en gran medida un desplazamiento espacial del sector industrial hacia economías subdesarrolladas. En esta línea, autores adscritos al enfoque del sistema-mundo o economía-mundo consideran justamente que son estos procesos de deslocalización y externalización internacional del centro hacia la periferia los que explican en gran medida la caracterización de semiperiferia a determinadas economías no desarrolladas (Arrighi y Drangel, 1986; Arrighi y cía, 1999; Arrighi y cía, 2003; Martínez, 2010).

\footnotetext{
${ }^{2}$ Si bien la evidencia empírica a nivel internacional para los países desarrollados, al menos cuando se analiza el sector servicios en su conjunto, sugiere la existencia de una relación negativa entre el peso del sector terciario y el crecimiento de la productividad. Sin embargo, esta imagen negativa del sector servicios ha sido refutada. Estas críticas se pueden resumir en tres: 1) tanto el mismo Baumol (2000) como otros investigadores han demostrado que solo un tercio de todos los servicios podría catalogarse como actividades de baja productividad mientras que el resto incluye sectores con crecimientos similares, o incluso mayores, que las manufacturas más dinámicas; 2) distintos trabajos empíricos han puesto de manifiesto la alta productividad que presentan algunas ramas de servicios, especialmente aquellas relacionadas con las TICs y las nuevas tecnologías; y, 3) algunos autores afirman que la naturaleza agregada de algunos estudios conduce a infravalorar la productividad real de algunas actividades terciarias (Maroto, 2013: 165).

${ }^{3}$ Desindustrialización entendida como la caída relativa del empleo manufacturero.

${ }^{4}$ Ley de Engel: es una observación empírica, llevada a cabo por primera vez por el estadístico alemán Ernst Engel (1821-1896), que constató que, con un conjunto de gustos y preferencias determinado, si los ingresos aumentan, la proporción del ingreso gastado en alimentos cae, aun cuando es probable que el gasto real en alimentación crezca en términos absolutos. (La elasticidad ingreso de la demanda de alimentos es inferior que uno). https://mherrerovelasco.wordpress.com/2010/10/01/la-ley-de-engel-del-siglo-xix-al-xxi/

5 En las cuentas nacionales, la tercerización de servicios antes in-house en empresas manufactureras genera la ilusión contable de cambios en el empleo / productividad (Grigera, 2011: 89).
}

Papeles de Europa

Vol. 29, Núm. 1 (2016): 51-81

http://dx.doi.org/10.5209/PADE.55011 
Orozco, Christian. ¿Reprimarización en la periferia?: El caso brasileño (2003-2013).

En cuanto a las aportaciones que desde la corriente poskeynesiana se presentan, los procesos de desindustrialización de las economías avanzadas se explican a partir de factores internos y externos. Los primeros están asociados -además de la cuestión de la evolución y divergencia de la productividad intersectorial- a la tesis de Clark (1940) que sostiene que la desindustrialización es una consecuencia natural del desplazamiento de la demanda de bienes industriales hacia un mayor consumo de servicios (salud, cultura, ocio, etc). En segundo lugar, desde este enfoque el factor externo clave que explica la desindustrialización de las economías avanzadas es la mayor intensificación de la competencia de otras economías que cuentan con crecientes ventajas competitivas en el sector industrial (Fontagné y Lorenzi, 2005). En cuanto a los efectos de este proceso caben destacar los planteamientos sobre crecimiento económico formulados por el economista húngaro Nicolás Kaldor (1966, 1967). En este sentido, las conocidas como leyes de Kaldor-Verdoorn establecen que la tasa de crecimiento de una economía está directamente relacionada con el sector industrial, así pues, dicho sector constituiría el motor del crecimiento. Dicha interconexión se debe sustancialmente al efecto multiplicador de la industria, al efecto de arrastre hacia atrás y hacia adelante que presenta el sector industrial y a las economías de aprendizaje que se manifiestan a medida que avanza la división del trabajo y la especialización en la producción en un contexto de expansión manufacturera (Márquez y Pradilla, 2008).

Por otra parte, para ciertos autores marxistas y, sobre todo, regulacionistas, el proceso de desindustrialización surge a partir de los años setenta y mediados de los ochenta, durante el periodo de entronización del neoliberalismo, como una manifestación evidente del agotamiento del anterior régimen o patrón de acumulación del capital sustentado en el intervencionismo estatal y en el fordismo. Desde este enfoque, la desindustrialización es entendida como un "proceso de reestructuración capitalista" (Grigera, 2011: 94), referido a un espacio territorial concreto definido como la reducción de su base industrial durante un periodo de medio o largo plazo, cristalizándose en: primero, la quiebra definitiva de empresas industriales (ponderado por su tamaño para evaluar su importancia en el proceso); segundo, la caída del número total de empleados industriales; tercero, la reducción absoluta del capital fijo y/o del ritmo de su formación; y, cuarto, la caída del volumen de producción industrial medido en productos físicos, en valor total o agregado. Cuando varias de estas variables experimentan una tendencia decreciente en términos reales (valores totales) en un periodo de medio o largo plazo, estaríamos ante un proceso de desindustrialización absoluta.

Lógicamente, la desindustrialización puede manifestarse también en términos relativos, es decir, la pérdida de peso o participación de la industria de un ámbito territorial, siguiendo sus distintas variables básicas, en el total de la economía local, o en el total del sector industrial nacional, o de la economía nacional en su conjunto, aunque no se generen pérdidas absolutas (Márquez y Pradilla, 2008). Así pues, si bien la caída permanente e incesante de la fuerza de trabajo industrial en un área concreta es un indicador muy relevante no podemos inferir inmediatamente que se esté produciendo un proceso de desindustrialización, puesto que puede darse el caso de que la composición orgánica del capital esté creciendo, y por tanto, aunque la fuerza de trabajo se reduzca el volumen de mercancías industriales se mantenga constante, o incluso, esté creciendo fruto de un proceso de "cambio tecnológico acelerado en los procesos de trabajo con la computarización y robotización de las 
Orozco, Christian. ¿Reprimarización en la periferia?: El caso brasileño (2003-2013).

fábricas. En este caso, hablaríamos de un incremento de la productividad del trabajo, que no implica desindustrialización" (ibíd.: 25).

La consideración marxista de la desindustrialización, desde este enfoque, entiende este proceso como una forma de reestructuración productiva. Así pues, los procesos de desindustrialización basados en la relocalización de las unidades de producción pueden inducir procesos de industrialización o dirigirse hacia ellos en las economías en las que desembarcan estos capitales. Así pues, la concepción del proceso de desindustrialización no es absoluta, sino más bien relativa, es decir, si atendemos a la variable espacial del proceso, tenemos que el desmantelamiento industrial de un espacio geográfico puede traducirse o no en proceso de industrialización de otros territorios (Márquez y Pradilla, 2008).

"El libre mercado y la libre competencia entre unidades productivas, sobre todo entre países y/o metrópolis asimétricos en términos de desarrollo tecnológico y productividad, o entre industrias nacionales y trasnacionales de diverso nivel de desarrollo, internas y externas, son factores de desindustrialización porque las industrias menos desarrolladas deben enfrentar una competencia desigual en el mercado con otras más productivas y con menores precios de producción, lo que las lleva a la pérdida de mercados, de ganancias, y a la desaparición" (Márquez y Pradilla, 2008: 41).

Finalmente, Márquez y Pradilla (2008: 31) consideran que los procesos de desindustrialización que experimentan las economías periféricas presentan una serie de rasgos históricos y estructurales muy particulares. Tanto Brasil como la mayoría de las economías latinoamericanas se industrializan de forma tardía, aproximadamente doscientos años más tarde que en Europa, de la mano de una estrategia de sustitución de importaciones, especialmente a partir de los años treinta, y en el marco de un régimen de acumulación proteccionista y dónde el intervencionismo del Estado era la norma, con sus particularidades nacionales, en las economías capitalistas tras la Segunda Guerra Mundial.

Para entonces, las economías europeas y estadounidense contaban con un sector industrial con un elevado nivel de tecnificación productiva, sus requerimientos de mano de obra eran decrecientes, y la producción en masa propia del taylorismo y el fordismo se había consolidado. Así pues, la transferencia de estas características a la incipiente industria latinoamericana por medio de las corporaciones transnacionales y los bienes de capital importados "definieron la relación entre capital y trabajo, y dieron lugar al desempleo estructural que prevalece desde entonces en el mercado laboral". En este contexto, un rasgo clave del mencionado "proceso de restructuración capitalista" fue la concentración y centralización del capital liderada por los monopolios $y$, especialmente, por las empresas transnacionales que desempeñaron un rol de primer orden en el proceso de industrialización de Latinoamérica, pasaron a ser los jugadores dominantes, aprovechando al máximo las barreras proteccionistas nacionales y los incentivos estatales que caracterizaban este periodo (Fajnzylber y Martínez, 1976).

En general, se considera que el proceso de desarrollo industrial latinoamericano por sustitución de importaciones (ISI) se puede dividir en dos fases o etapas. La primera, conocida como industrialización fácil, desarrollada entre 1930 y 1950 y centrada en la industrialización sustitutiva de bienes de consumo inmediato, Y la segunda, sustitutiva de bienes de consumo duradero o intermedios, se cumple solo parcialmente de 1950 a 1970. Pese al intento de completar el circuito interindustrial a 
Orozco, Christian. ¿Reprimarización en la periferia?: El caso brasileño (2003-2013).

través del avance hacia la producción interna de medios de producción, la segunda etapa no logró grandes progresos en gran medida debido a la dependencia tecnológica en relación a las economías avanzadas, restringida desde una fase temprana del proceso, la industrialización latinoamericana se puede adjetivar como trunca (Fajnzylber, 1983).

Tras el final de estas etapas, la agudización de las contradicciones y limitaciones del proceso industrializador supusieron el agotamiento de este patrón de acumulación, desencadenando a partir de los años ochenta una profunda crisis -de deuda en un primer momento- que facilitó, de forma desigual por países, pero de forma generalizada, la aplicación de los programas de ajuste neoliberal propugnados por los organismos económicos internacionales (FMl y Banco Mundial). En este contexto:

"Sin concluir su industrialización, o aun sin iniciarla en algunos países, con grandes ciudades pobladas por una masa de desempleados no absorbidos por la industria existente, dependiendo férreamente de las empresas trasnacionales dominantes en las economías nacionales, de las instituciones financieras multilaterales y de los países hegemónicos, los países latinoamericanos entraron a la libre circulación de capitales, mercancías e informaciones, a la llamada globalización" (Márquez y Pradilla, 2008: 32).

En este sentido, en el caso particular de la experiencia latinoamericana, podemos encontrar una serie de factores externos e internos que explican en gran medida el agotamiento de la ISI. Los externos están vinculados a la existencia de un modelo exportador inalterado, el cual sigue siendo muy dependiente de la importación de bienes de capital del exterior, y con una proyección internacional limitada. Por otro lado, los factores internos refuerzan este esquema, puesto que la limitada competitividad de los productos fabricados por estas economías se asocia a la consolidación de unos niveles salariales particularmente elevados, en comparación con países competidores directos como los de los países asiáticos (Fajnzylber, 1983).

No obstante, el debate sobre el fenómeno de la desindustrialización no se agota aquí, sino que, además, desde la academia se ha formulado la existencia de nexos de causalidad entre la abundancia y/o dependencia de los recursos naturales de una economía y su pobre desempeño económico, productivo e industrial.

\subsection{El proceso de desindustrialización y los recursos naturales}

El planteamiento descrito anteriormente se conoce en la literatura económica con el nombre de la "maldición de los recursos". Ross (1999: 298) señala la existencia de cuatro factores que explicarían el hecho de que las economías ricas en recursos naturales presenten bajas tasas de crecimiento económico:

a) el deterioro de los términos de intercambio (Davis, 1995: 1766);

b) la inestabilidad de los mercados internacionales de productos básicos;

c) los reducidos nexos económicos entre los sectores no vinculados al recurso;

d) la conocida como "enfermedad holandesa"6.

\footnotetext{
6 "Un fenómeno denominado así por la experiencia holandesa con las exportaciones de gas después del descubrimiento de grandes campos petrolíferos en el Mar del Norte en la década de 1960. El aumento de las exportaciones de gas holandés generó un flujo de divisas que apreció el florín, perjudicando a otros sectores de exportación y la competitividad del país" (Ramírez, 2014: 115). Traducción propia.

Papeles de Europa 
Orozco, Christian. ¿Reprimarización en la periferia?: El caso brasileño (2003-2013).

El origen de este último concepto se encuentra en el semanario inglés The Economist (1977). Sin embargo, tendremos que esperar hasta los años ochenta para encontrar su primera formulación académica en investigaciones clásicas de Buiter y Purvis (1980), Corden y Neary (1982), Bruno y Sachs (1982). "La enfermedad holandesa" plantea que el rápido crecimiento de las exportaciones de commodities por parte de una economía puede llegar a generar efectos negativos en otros sectores, así como en el comportamiento de la economía en su conjunto (Ramírez, 2014: 115). Las economías exportadoras de recursos minerales son vulnerables a experimentar esta enfermedad, especialmente cuando estos sectores experimentan un importante auge en términos de volumen y/o precio. En esencia, la aparición de la enfermedad holandesa en una economía da como resultado un proceso de desindustrialización de la misma a medio plazo (Davis, 1995: 1768).

Tres son los efectos que se asocian al desarrollo de este fenómeno: primero, una apreciación del tipo de cambio real provocado por el auge de las exportaciones de recursos naturales (Gylfason y Nguessa, 2014); segundo, una marcada tendencia del sector en auge a drenar capital y trabajo de los sectores industrial y agrícola efecto crowding-out-, aumentado sus costes de producción (Sachs, 1995; Sachs y Warner, 2001) y, tercero, ambos efectos pueden conducir a una caída de las exportaciones de los sectores agrícola y manufacturero, pudiendo repercutir en un aumento de los costes de los bienes y servicios que no son susceptibles de ser importados (Ross, 1999; Gylfason y Nguessa, 2014).

Sin embargo, el mismo fenómeno se manifiesta de dos formas diferentes directamente asociadas a las estructuras productivas de las economías a las que afecta. Si bien en el caso de las economías desarrolladas la enfermedad holandesa puede dar lugar a procesos de desindustrialización, esto no ocurre en la mayoría de las economías subdesarrolladas, donde es difícil identificar rasgos de desindustrialización en países que cuentan con sectores industriales estructuralmente débiles y poco consolidados (en contraste con la diversificada economía holandesa, donde éstos síntomas pueden ser más fácilmente identificados). Ramírez (2014) considera que en el caso de las economías subdesarrolladas la enfermedad no se manifiesta en forma de desindustrialización, sino en forma de barreras a la diversificación productiva generadas por el auge de los ingresos del sector exportador intensivo. Una situación, esta última, más cercana al caso boliviano que al brasileño o argentino.

En esta misma línea, en torno a los debates académicos y políticos que en América Latina se han producido a partir del boom de las materias primas de los últimos años cabe resaltar aquellas aportaciones que defienden que la reprimarización ${ }^{7}$ de las economías latinoamericanas se puede entender como un proceso de cambio estructural (Ferreira y Cutrim, 2011). Así pues, autores más cercanos al estructuralismo y al dependentismo como Slipak (2014), Bolinaga y Slipak (2015), Grigera (2012), Nadal (2009) formulan una identificación directa del proceso de desindustrialización como un proceso de reprimarización de la economía:

\footnotetext{
7 Pese a la actualidad del término de "reprimarización de la economía", el grupo FLACSO ha empleado el término ampliamente desde mediados de los años setenta. Por ejemplo, O’Donnel (1977) reflexionaba sobre el Estado burocrático autoritario y su vinculación con procesos de "reagrarización" o "reprimarización" (ibíd.: 191).
}

Papeles de Europa 
Orozco, Christian. ¿Reprimarización en la periferia?: El caso brasileño (2003-2013).

\begin{abstract}
"La reprimarización se define como un proceso de reconfiguración de la matriz productiva hacia actividades de menor contenido de valor agregado, generalmente actividades primarioextractivas, así como también maquilas. Es decir, se trata de una reorientación de los factores de producción de una economía hacia procesos de menor contenido de conocimiento. Esto ocurre por reducir la participación en aquellas fases productivas de las cadenas globales de valor de mayor intensidad tecnológica, por lo tanto se trata de un proceso que ocurre de manera gradual y se vincula con fenómenos de carácter estructural, y no con que una coyuntura se incremente o disminuya la participación en el producto o las exportaciones del sector industrial...Este proceso limita las posibilidades para que los países de la región [América Latina] desarrollen transformaciones estructurales en sus matrices productivas, las cuales podrían permitirles una inserción comercial internacional basada en actividades económicas de mayor dinamismo" (Slipak, 2014: 4; Bolinaga y Slipak, 2015: 36).
\end{abstract}

En cuanto a las causas que explican estos procesos podemos encontrar una serie de estudios que apuntan a:

a) la acentuación y consolidación de los programas de ajuste neoliberal que se iniciaron durante los años ochenta y noventa en América Latina, es muy significativo, además, que esta causa esté vinculada también a los procesos de desindustrialización de las economías periféricas de finales del siglo XX (Carcanholo, 2014);

b) el destacado crecimiento de la demanda mundial de materias primas y el consecuente aumento de sus precios (Carcanholo, 2010; Ferreira y Cutrim, 2011; Gonçalves, 2011);

c) la acentuación del carácter dependiente del continente no solo en relación a los países centrales sino también en relación con otras economías no desarrolladas como China (Gonçalves, 2011; Carcanholo, 2014).

Desde estos enfoques se considera que la vinculación desindustrializaciónreprimarización es un fenómeno característico de las economías latinoamericanas en las últimas décadas, especialmente en aquellos países categorizados como semiperiféricos, como Argentina y Brasil (Grigera, 2012; Slipak, 2014). Desde esta perspectiva teórica, el concepto de reprimarización está asociado a la reversión de las transformaciones que se gestaron durante el periodo industrializador y las externalidades positivas que se generaron (Grigera, 2012).

\title{
1.3. Balance y pregunta de investigación
}

En base a la revisión de literatura previamente realizada y considerando que nuestro objeto de estudio es la economía brasileña, resulta pertinente plantear las consideraciones siguientes.

Primera, en torno al debate sobre las causas que están detrás del fenómeno de la desindustrialización podemos distinguir tres dinámicas diferentes (siendo la primera la más estudiada en la literatura):

a) procesos de desindustrialización propios de una lógica de acumulación "natural", vinculada a las propias características de una economía avanzada, tales como su alta productividad en la industria, el fuerte crecimiento de su sector terciario y la internacionalización de su capital;

b) procesos de desindustrialización característicos de economías periféricas dependientes, relacionados con el abandono paulatino del Estado como actor relevante del desarrollo industrial, la enorme dependencia de los capitales $-\mathrm{y}$ tecnologías- extranjeros, y, en general, la debilidad secular de los procesos Papeles de Europa 
Orozco, Christian. ¿Reprimarización en la periferia?: El caso brasileño (2003-2013).

industriales previos. Siendo este último caso el que, como veremos más adelante, mejor se ajusta a las características de la experiencia histórica brasileña;

c) la tercera está asociada al boom exportador de recursos naturales de una economía, desde esta perspectiva hablábamos de los fenómenos de enfermedad holandesa y reprimarización. En este sentido, cabe destacar que en muchas ocasiones la literatura no distingue o utiliza como sinónimos los términos de desindustrialización y reprimarización, sin embargo, como hemos podido resaltar son dos conceptos diferenciados.

Segunda, respecto a la definición y conceptualización del proceso, aunque con ciertas discrepancias importantes, la desindustrialización como tercerización de una economía (central o periférica) se entiende como la pérdida de importancia cualitativa y/o cuantitativa del sector industrial en favor del sector servicios 0 terciario. Ahora bien, tanto los rasgos estructurales que caracterizan a la economía brasileña, como las propias particularidades históricas de su proceso de desarrollo industrial, nos conducen a definirla como una economía periférica dependiente, y por tanto, el proceso de desindustrialización desde el punto de vista de sus factores determinantes y de las implicaciones del proceso de desindustrialización para el funcionamiento de la economía, en el caso de evidenciarse, no se trataría de una fenómeno equivalente al que las economías centrales llevan experimentando desde la década de los setenta. En este sentido, investigadores como Fajnzylber (1983), Dasgupta y Singh (2006), Palma (2005), y Salama (2012) han hablado de la existencia de una industrialización "trunca" o una desindustrialización "precoz".

Por otra parte, aunque el fenómeno de "la enfermedad holandesa" se ha estudiado en países desarrollados y subdesarrollados tampoco consideramos adecuada esta perspectiva analítica debido a la limitación que presenta para explicar completamente la experiencia de Brasil. Ésta está relacionada con el hecho de que la enfermedad reduce la causa de la desindustrialización al coyuntural boom exportador de las materias primas, y, consecuentemente a la apreciación de la moneda nacional, $y$, al mismo tiempo, a un reordenamiento de los factores productivos entre sectores. Por tanto, si bien consideramos que la cuestión monetaria es importante para el presente análisis, sostenemos también que es necesario analizarlo desde un enfoque histórico-estructural para aprehender el fenómeno de una forma más completa. En la línea de Alves y cía (2008: 16) entendemos que "la tendencia a la reprimarización se configura como un proceso estructural, y no solo como un fenómeno cíclico", por el cual, una economía que cuenta con un considerable desarrollo industrial y abundante en uno o una pequeña cesta de materias primas experimenta un importante crecimiento de su sector primario -e industrial extractivo- en detrimento de su base industrial, especialmente, la más puntera en términos tecnológicos, siendo, generalmente, el catalizador de este proceso un incremento muy destacado del nivel de precios de las materias primas. $\mathrm{Y}$, finalmente, se asume que los procesos de desindustrialización tienen consecuencias directas sobre variables macroeconómicas tales como el crecimiento económico, los niveles de productividad y el empleo. Sin embargo, esto último no será objeto de estudio en el presente trabajo.

En resumen, a partir de estas inferencias podemos considerar la posibilidad de que la economía brasileña esté experimentando un doble proceso: por una parte, a partir de finales de los ochenta, un proceso de desindustrialización -prolíficamente 
Orozco, Christian. ¿Reprimarización en la periferia?: El caso brasileño (2003-2013).

contrastado en la literatura- asociado a economías periféricas dependientes con una base industrial ciertamente relevante; y, por otra, un proceso de desindustrialización asociado al fenómeno de la reprimarización a partir de los albores del siglo XXI. Es decir, existe una serie de evidencias que nos permiten constatar el desarrollo de un proceso de desindustrialización en Brasil, cuyo inicio y causas son previas a la fase del boom de las materias primas (2003-2013), y, por tanto, el proceso de reprimarización (en el caso de manifestarse) que sobreviene a partir de ese periodo, solo puede ser valorado su alcance considerando los antecedentes del proceso de industrialización y desindustrialización previo.

En base a estas apreciaciones, nos planteamos como pregunta de investigación "constatar si entre el periodo 2003-2013 se ha producido o no un proceso de reprimarización de la economía de Brasil”. Para ello, en el siguiente apartado describimos sucintamente los rasgos que caracterizan el ciclo de industrialización y declive de la industria brasileña como antecedentes del más reciente proceso que nos disponemos a analizar y cuya dinámica, en ciertos sectores, no quedó extinguida con el inicio del boom de las materias primas. Y, más adelante, estudiaremos una serie de indicadores fundamentales acordes a la definición que hemos dado del fenómeno, focalizándonos, por tanto, en el estudio de la evolución económica del sector primario e industrial extractivo, los cambios en los niveles tecnológicos de los productos industriales, y las fluctuaciones del real brasileño. Específicamente, estos indicadores son:

a) la distribución sectorial del PIB, distinguiendo el comportamiento de los sectores vinculados a los recursos naturales y los no asociados, y el contenido local de los sectores industriales por intensidad tecnológica;

b) la distribución sectorial de la población ocupada, separando aquellas actividades vinculadas a los recursos naturales de todas las demás, y la distribución de la población empleada agrupada por niveles tecnológicos;

c) los principales productos exportados e importados por Brasil, sus contenidos tecnológicos, y demás indicadores comerciales;

d) la tasa de cambio efectiva real del real brasileño.

Por una parte, cabe resaltar que cuando nos referimos a sectores o actividades vinculadas a los recursos naturales en este trabajo nos estaremos refiriendo sustancialmente a dos: el sector agropecuario y las industrias extractivas. Por otra parte, no incluimos el sector de los derivados del petróleo -aunque es una industria vinculada a los recursos naturales- porque mientras que las industrias extractivas se incluyen en el grupo de sectores de baja tecnología, los derivados del petróleo se incluyen en el de alta, y, por tanto, una evolución positiva de este último no significa necesariamente que se esté produciendo un proceso de reprimarización de la economía brasileña.

\section{ANTECEDENTES HISTÓRICOS Y ESTRUCTURALES}

\subsection{Industrialización y desindustrialización dependientes: el caso de Brasil}

En la literatura especializada existe un consenso generalizado en situar en la década de los años treinta el origen del proceso de industrialización brasileño (Begué, 2001; Cano, 2007; Álvarez, 2009; Pereira, 2012). Dos son los principales factores que propician este proceso, por una parte, en el plano internacional destaca la grave 
Orozco, Christian. ¿Reprimarización en la periferia?: El caso brasileño (2003-2013).

crisis mundial que estalla en esta época y las dos guerras mundiales, produciendo importantes alteraciones en los patrones de abastecimiento de bienes manufacturados del centro a la periferia. Por otra parte, a nivel interno, la llegada de Getulio Vargas al poder en Brasil supone el surgimiento de un Estado intervencionista propiamente dicho, la década de los treinta da lugar a un periodo de tránsito de un modelo de acumulación primario-exportador ${ }^{8}$ basado en la dominación de la antigua oligarquía terrateniente a un nuevo modelo desarrollista impulsado por nuevos grupos sociales dominantes ${ }^{9}$ que se insertan en el aparato del Estado.

Hasta los años cuarenta el desarrollo del sector industrial se caracteriza por producirse de forma pausada, desorganizada, y sin planificación. No será hasta principios de los años cincuenta cuando el Estado brasileño asuma como propio los planteamientos desarrollistas teorizados por la CEPAL y el BNDES (la única forma que una economía puede desarrollarse es a través de su industrialización, y ésta debía ejecutarse a través de una fuerte intervención estatal). Así pues, es en esta época cuando se inicia un proceso de sustitución de importaciones, produciéndose una progresiva tendencia a la caída del peso relativo de las importaciones de bienes de consumo (compensada por producción nacional) respecto a los bienes de equipo y los combustibles (Taïeb y Barros, 1989: 23).

Pese a los exitosos resultados industriales que se obtienen (en el periodo 1930-1980 mientras que la producción total se multiplica por nueve, la del sector industrial lo hace por más de doce), a partir de mediados de los años sesenta ${ }^{10}$ surgen las primeras evidencias del agotamiento de este modelo, y a pesar de que en los años setenta se lazaron el I Plan Nacional de Desarrollo (1972-1974) y el II Plan Nacional de Desarrollo (1975-1979) con la intención de completar el proceso de sustitución de importaciones, éstos resultaron poco efectivos. El modelo ha entrado en una fase de crisis terminal (Begué, 2001: 190).

Además, debemos considerar que este proceso acelerado de industrialización iniciado en 1930 presentaba una serie de limitaciones y rasgos que nos permiten caracterizar al proceso de industrialización brasileño como dependiente y poco consolidado. Primero, los insuficientes niveles de acumulación y concentración de capital necesarios para impulsar el nacimiento de una vigorosa industria pesada (Pereira, 2015: 93). Segundo, la escasez de capital doméstico necesario para liderar el proceso de acumulación, y el mantenimiento de una tecnología anticuada, atrasada, y, además, dependiente de los capitales extranjeros, la creación de un núcleo endógeno de desarrollo es prácticamente inexistente (Kohli, 2004: 129; Evans, 1979). Y tercero, los acotados recursos con los que contaba el Estado para impulsar el proyecto industrializador -generalmente la creación directa de empresas públicas se incoaba cuando ni los industriales brasileños ni los capitales extranjeros invertían en un sector determinado-, así pues, los ingresos públicos eran sumamente

\footnotetext{
${ }^{8}$ A principios del siglo XX Brasil se inserta en el proceso de división internacional del trabajo como exportador monoproductor primario: las exportaciones de café suponen el 80\% del total de exportaciones del país (Begué, 2001: 169).

9 "Esta alianza-reformista `anti-oligárquica' se apoya en una movilización controlada de las masas populares, principalmente urbanas, en una experiencia de participación limitada al tiempo que autoritaria, y en un modelo de desarrollo nacional basado en la industrialización como estrategia principal”. (Begué, 2001: 176)

${ }^{10}$ En términos políticos, el golpe de Estado militar de 1964 supone la deposición de fracción de la burguesía local desarrollista nacionalista, y su sustitución por una fracción más internacionalizada (Begué, 2001: 190).

Papeles de Europa 
Orozco, Christian. ¿Reprimarización en la periferia?: El caso brasileño (2003-2013).

dependientes de los aranceles y los impuestos indirectos, de tal forma que cuanto más crecían la inversión y el gasto público, la deuda pública lo hacía también, especialmente la deuda externa ${ }^{11}$ (Kohli, 2004: 162-163). En esencia, en Brasil se consolida un capitalismo industrial débil, en el que tanto el empresariado local, como la élite estatal, y los inversores extranjeros se mostraron satisfechos de que la economía brasileña produjese principalmente productos de bajo valor añadido al abrigo de barreras proteccionistas al comercio y demás medidas que blindaban el mercado interno de la competencia internacional (Kohli, 2004: 189).

Del mismo modo que el proceso de industrialización brasileño -periférico, dependiente y poco consolidado- presenta una serie de elementos que lo diferencian del de las economías más avanzadas, lo mismo ocurre con el fenómeno de la desindustrialización. Así, en contraste, en los países avanzados la cuestión de la desindustrialización se remonta a la década de los setenta, siendo profundizada por la aplicación de las políticas neoliberales puestas en marcha en las décadas posteriores. No solo eso, sino que las economías desarrolladas aún mantienen una proporción entre un $30 \%$ y un $40 \%$ de la producción de bienes de capital en sus estructuras productivas; y, además, sus sectores terciarios presentan una participación muy elevada en aquellas actividades con un valor añadido mayor vinculadas a los sectores más productivos, particularmente servicios industriales. En este sentido, no podemos olvidar dos cuestiones. Primera, las cadenas globales de valor siguen teniendo como protagonista destacado a las economías más desarrolladas -particularmente sus corporaciones transnacionales-. Segunda, la reestructuración productiva de estas economías, al menos en un principio, se categorizó como natural, positiva, o incluso deseable. Esto no ocurre en el caso de las economías subdesarrolladas (Pereira, 2015: 1997-1998).

Figura 1. PIB pc en PPA y Participación de la industria en el PIB
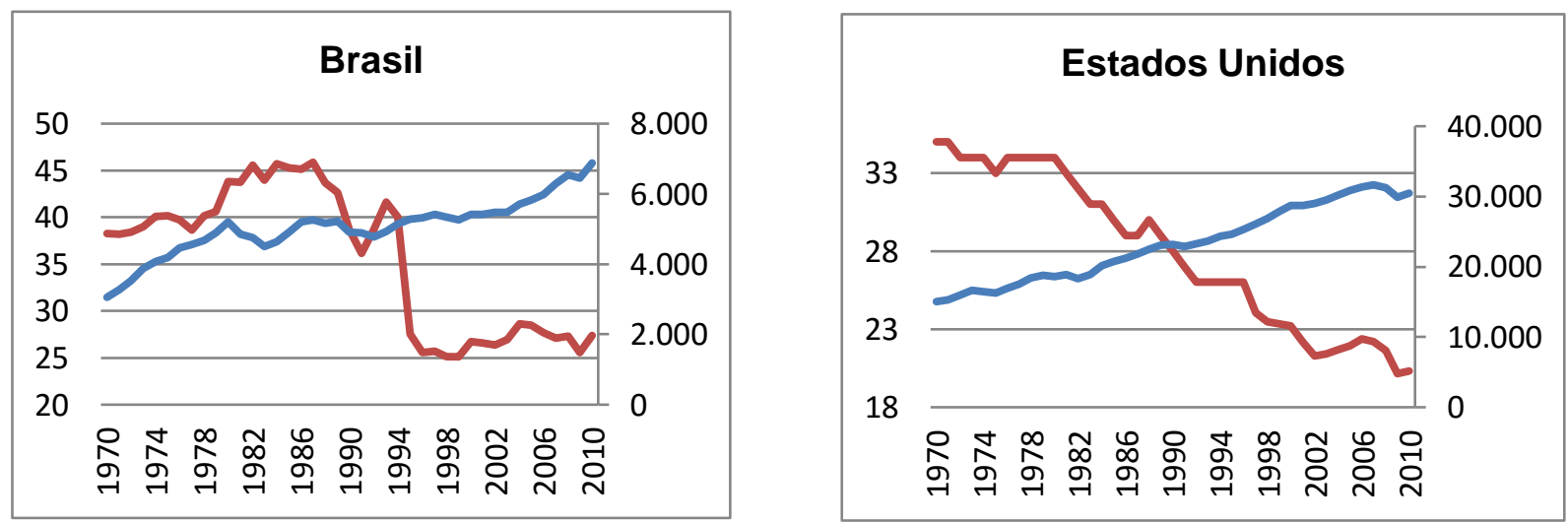

\footnotetext{
${ }^{11}$ La crisis de la deuda externa de los años ochenta interrumpe drásticamente esta dinámica de crecimiento y transformaciones. Desde entonces hasta la actualidad la actividad económica crece a un ritmo muy reducido: si en las tres décadas anteriores el PIB se incrementa a una tasa media anual del 7,6\%, en los siguientes veinticinco años ni siquiera alcanza el 2,2\% anual, de forma que el PIB per cápita apenas crece (lo hace a una tasa del 0,3\%). El desempeño del sector industrial es aún peor, se incrementa sólo al 1,2\% anual, habiéndolo hecho al 8,7\% al año durante las décadas anteriores (Medialdea, 2009: 45).
}

Papeles de Europa

Vol. 29, Núm. 1 (2016): 51-81

http://dx.doi.org/10.5209/PADE.55011 
Orozco, Christian. ¿Reprimarización en la periferia?: El caso brasileño (2003-2013).
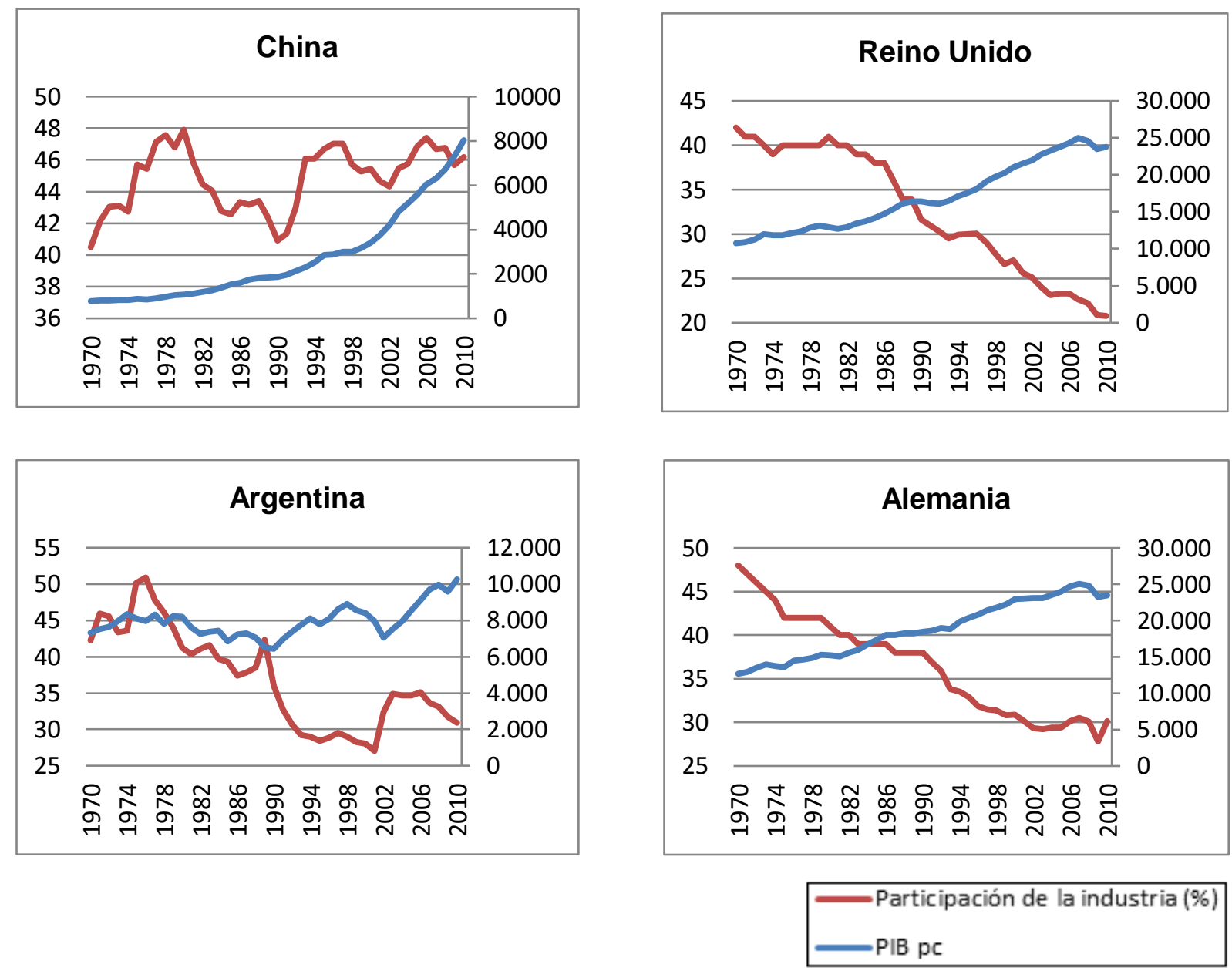

Fuentes: Elaboración propia a partir del Banco Mundial y Maddison Project Databas

En esta línea, la Figura 1 representa una primera aproximación al fenómeno de la desindustrialización (no es el caso de China) en varias economías, entendido como una reducción de la participación del sector industrial en el total de la producción. Si comparamos el caso brasileño con el resto de países podemos apreciar que en Brasil (al igual que en Argentina) la caída de la participación relativa de la industria en el conjunto de la economía se produce cuando el respectivo PIB pc está muy por debajo de lo que se observa en el caso de las economías más desarrolladas. Así pues, autores como Dasgupta y Singh (2006), Palma (2005) y Messenberg (2012) plantean que en Brasil se podría hablar de un fenómeno de desindustrialización precoz.

En el mismo sentido, si analizamos las tasas de crecimiento anual promedio del PIB y los tres sectores de la economía, podemos apreciar cambios significativos en el comportamiento de las variables. A partir de la década de 1980, y especialmente la de $1990^{12}$ no solo se ralentiza considerablemente la dinámica de crecimiento de la economía brasileña, sino que el crecimiento de la industria es menor que el crecimiento de la economía en su conjunto. En este sentido, es importante observar que desde una perspectiva de largo plazo los primeros rasgos de

\footnotetext{
${ }^{12}$ En 1994 se aplica el llamado Plan Real, un programa de ajuste estructural -sin una participación directa del FMI- centrado en: una estrategia de estabilización monetaria, la liberalización del comercio, la apertura financiera, un cambio patrón monetario y la privatización de grandes empresas (Medialdea, 2009).

Papeles de Europa

Vol. 29, Núm. 1 (2016): 51-81

http://dx.doi.org/10.5209/PADE.55011
} 
Orozco, Christian. ¿Reprimarización en la periferia?: El caso brasileño (2003-2013).

desindustrialización de la economía brasileña se ubican en los años ochenta, y, por tanto, no es un fenómeno que se pueda vincular íntegramente al boom de los precios de las materias primas de principios del siglo XXI.

Figura 2. Tasa de crecimiento anual medio de los sectores del PIB desde la oferta en \%

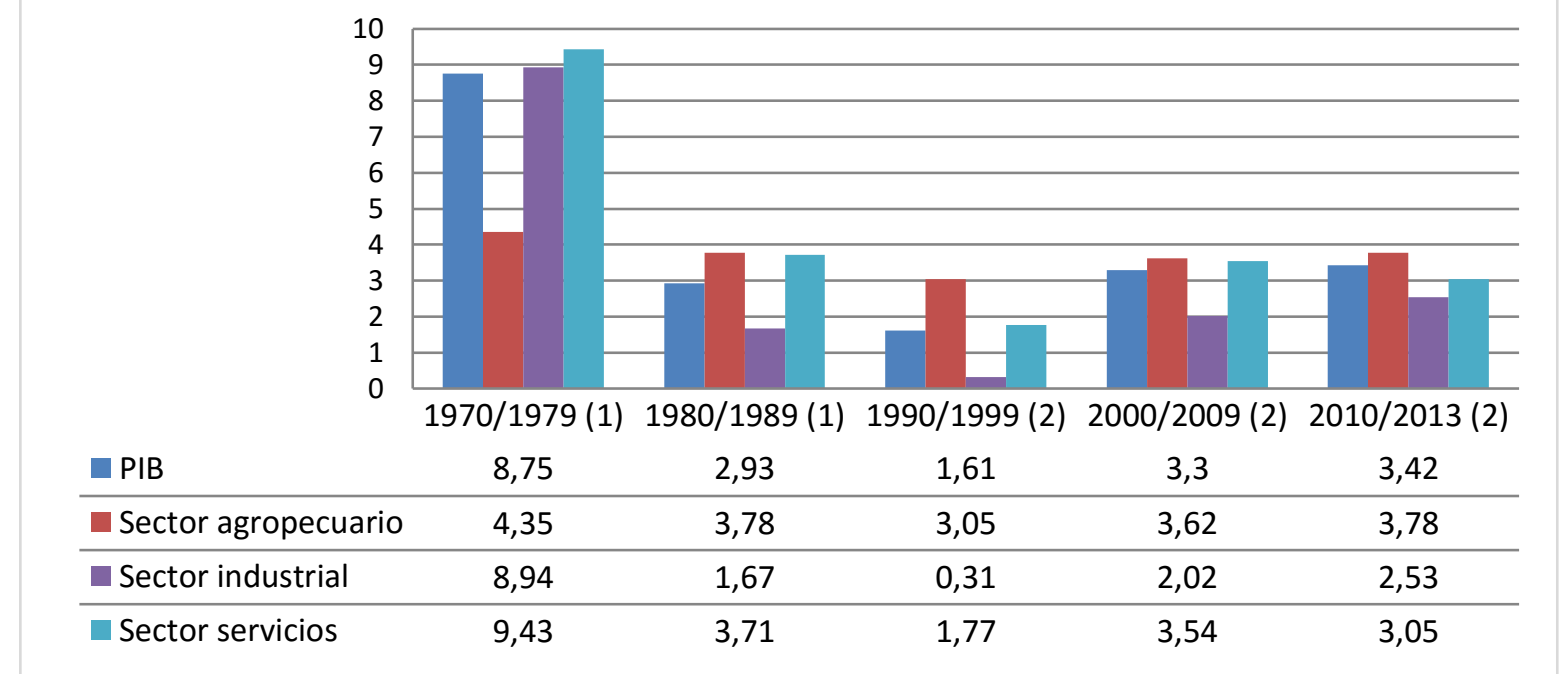

(1) PIB a coste de factores;

(2) PIB a precios básicos

Fuentes: Elaboración propia a partir de IBGE e Ipeadata.

Adicionalmente, observamos que, si bien el ritmo de crecimiento del sector primario se mantiene prácticamente estable, éste se convierte en el motor del crecimiento de la economía brasileña desde la década de los ochenta hasta la actualidad.

\section{3. ¿REPRIMARIZACIÓN EN BRASIL ENTRE 2003 Y 2013?}

\subsection{Participación sectorial en el PIB y contenido local}

La primera de las variables que analizamos es la participación sectorial relativa en el PIB de los tres sectores de la economía brasileña. A grandes rasgos, constatamos una tendencia hacia un mayor peso relativo de los servicios en detrimento de los sectores primario y secundario, siendo este último el que más se deprime.

Figura 3. Distribución sectorial del PIB en \%

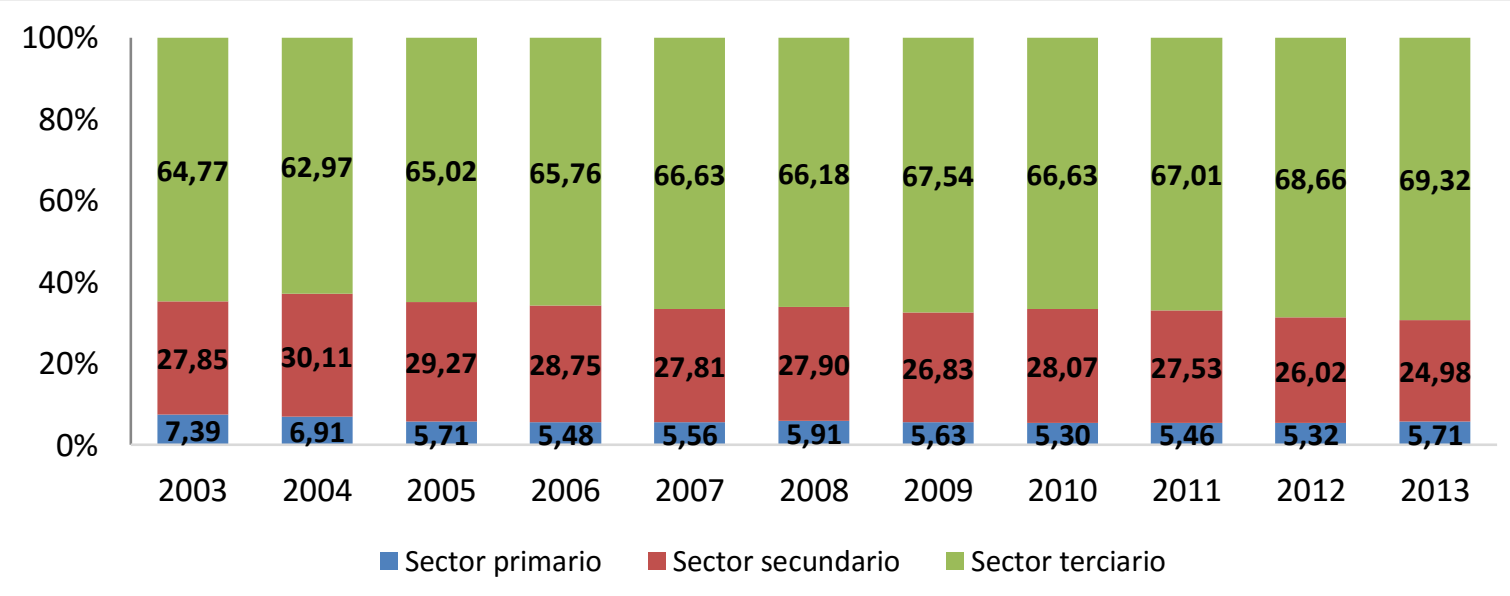

Fuente: Elaboración propia a partir de IBGE.

Papeles de Europa 
Orozco, Christian. ¿Reprimarización en la periferia?: El caso brasileño (2003-2013).

Ahora bien, diferenciando el comportamiento del PIB real vinculado a los recursos naturales (incluyendo al sector agropecuario y a las industrias extractivas) del resto de sectores, podemos afirmar que éste representa aproximadamente un $10 \%$ de la economía brasileña, y aunque entre 2003 y 2013 su peso es mayor, solo lo es en menos de un $1 \%$ más. Sin embargo, si nos fijamos en los elementos que lo componen, descubrimos que son las industrias extractivas las que más protagonismo adquieren, creciendo a una media del 5,7\%, mientras que el sector agropecuario lo hace al 1,2\%.

Finalmente, para terminar el análisis de este bloque, en la Figura 4 (para detalle, véase Tabla 1 del anexo), está representado el valor añadido nacional por sectores industriales a través de la relación entre el valor industrial de transformación (VTI) y el valor bruto de transformación industrial (VBPI) ${ }^{13}$, obtenidos a partir de la base de datos de IPEA. Así pues, una caída de esta ratio significa que el valor añadido nacional de la producción está mermando.

Figura 4. Relación de VTI / VBPI por niveles tecnológicos

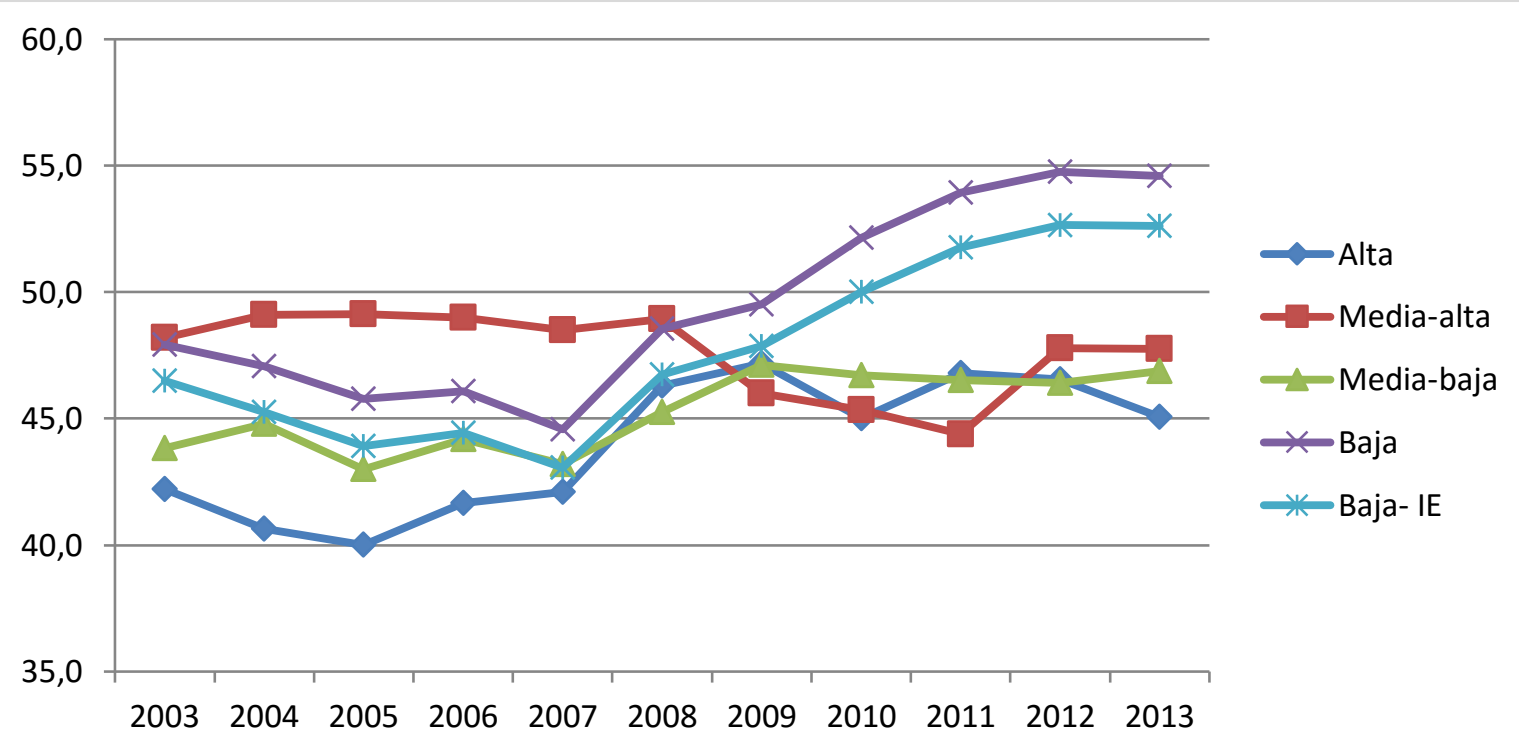

Fuentes: Elaboración propia a partir de IBGE.

Después de una década de caídas de la ratio VTI / VBPI, a partir del año 2005 (consolidándose en el 2007) la tendencia cambia de signo, el indicador empieza a crecer, y por tanto, el contenido local de los productos también. Esta recuperación está claramente dirigida por los sectores de baja intensidad tecnológica. Entre 20052013 aquellos sectores que experimentan un mayor crecimiento de la ratio VTI / VBPI son: la elaboración de coque (+49 puntos); las industrias extractivas $(+14$ puntos); y la fabricación de prendas de vestir y accesorios (+11 puntos). Por el contrario, las industrias con un peor rendimiento son las siguientes: la metalurgia de

\footnotetext{
${ }^{13}$ VBPI - corresponde a la suma de las ventas de productos industriales y servicios (ingreso neto industrial), la variación las existencias de productos terminados y en proceso, y la producción propia realizada para el inmovilizado.

VTI - corresponde a la diferencia entre el VBPI y el coste de las operaciones industriales (la suma del consumo de materias primas, materiales y componentes auxiliares, la compra de electricidad, consumo de combustible, partes y accesorios; y los servicios industriales y de mantenimiento y reparación de maquinaria y equipos relacionados con la producción proporcionados por terceros). Traducción de Google translate ( http://www.sidra.ibge.gov.br/ ).
}

Papeles de Europa 
Orozco, Christian. ¿Reprimarización en la periferia?: El caso brasileño (2003-2013).

metales no ferrosos y fundición (-8 puntos); las máquinas de oficina y equipos informáticos (-5 puntos); y los dispositivos electrónicos, material y equipos de comunicación (-3 puntos); es decir, productos de alta y media intensidad tecnológica. Cabe resaltar, además, el hecho de que el índice VTI / VBPI de bajo nivel tecnológico se mantiene sistemáticamente por encima de la misma ratio pero descontando la aportación de las industrias extractivas (IE), eso significa que estructuralmente dicho sector presenta un mayor contenido de valor añadido nacional que el resto de sectores de baja tecnología.

El análisis de estas variables nos conduce a poder afirmar que entre 2003 y 2013 :

a) el sector agropecuario representa un peso cada vez menor en el conjunto de la economía, a pesar de que en términos absolutos sigue creciendo;

b) el sector industrial también se deprime en términos relativos, perdiendo contenido local especialmente en aquellas actividades de mayor intensidad tecnológica (salvo el refino de petróleo que se mantiene estable a lo largo del periodo), y ganándolo los sectores de bajo contenido tecnológico, principalmente las industrias extractivas.

A continuación, nos centramos en observar que ocurre con la evolución de la población ocupada por sectores.

\subsection{Población ocupada por sectores}

Mientras que la población ocupada en el sector primario experimenta una considerable caída en términos relativos, pero también absolutos (entre 2003 y 2013 desaparecen cerca de un millón de empleos agropecuarios), los otros dos sectores crecen, el sector secundario aumenta un $1,5 \%$ su participación en el total del empleo, y el terciario un 4,3\%. De una forma más desagregada, las actividades que más población ocupada requieren son: el comercio, la restauración y los hoteles; la agricultura; y los servicios comunales, sociales y personales.

Es especialmente interesante observar también los cambios que experimenta la productividad intersectorial. Así, mientras que ésta crece tímidamente en el sector primario, en el sector secundario cae, y terciario ${ }^{14}$ se mantiene estable durante el periodo estudiado.

\footnotetext{
${ }^{14}$ Sector primario: en 2003 el 1\% de población ocupada crea el 0,37\% del PIB, en 2013 lo hace en un 0,4\%. Sector secundario: en 2003 el 1\% de población ocupada crea el 1,32\% del PIB, en 2013 lo hace en un 1,1\%. Sector terciario: en 2003 el 1\% de población ocupada crea el 1,1\% del PIB, en 2013 lo hace en un 1,1\%. 
Orozco, Christian. ¿Reprimarización en la periferia?: El caso brasileño (2003-2013).

Figura 5. Población ocupada por sectores en \%

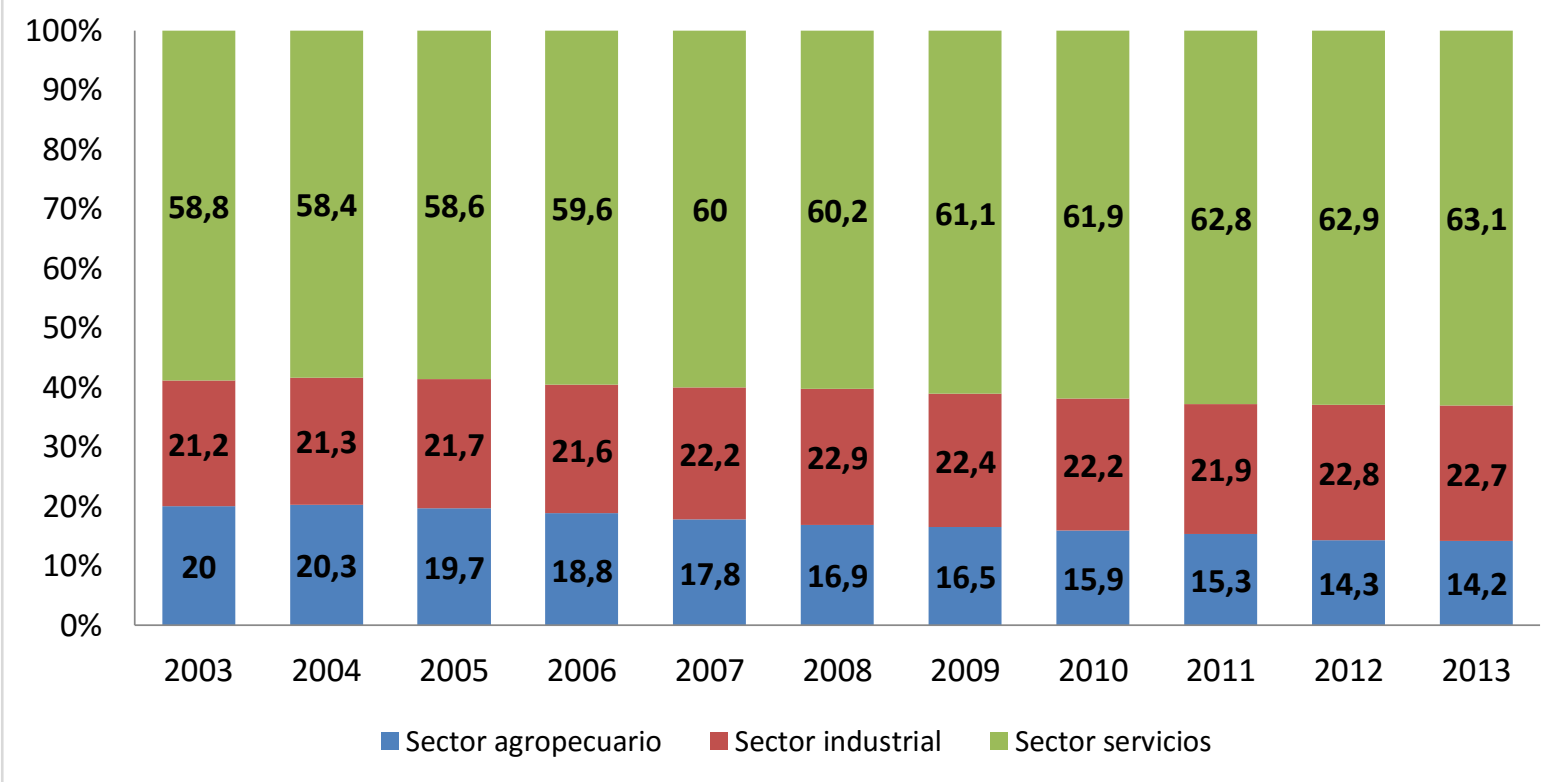

Fuente: Elaboración propia a partir de IBGE.

Por otra parte, si estudiamos el comportamiento de todos aquellos sectores relacionados con los recursos naturales, constatamos que entre 2003 y 2013 la caída de población ocupada en el sector agropecuario no es contrarrestada por el crecimiento del empleo vinculado a las actividades extractivas, y por tanto, en conjunto, el trabajo asociado a los recursos naturales cae en Brasil (un 5,8\% del total del empleo entre 2003 y 2013).

Más adelante, el siguiente indicador extraído de la base de datos de IBGE nos señala el número de personas ocupadas ${ }^{15}$ en los distintos sectores industriales brasileños clasificados por su intensidad tecnológica.

Figura 6. Población ocupada por niveles tecnológicos

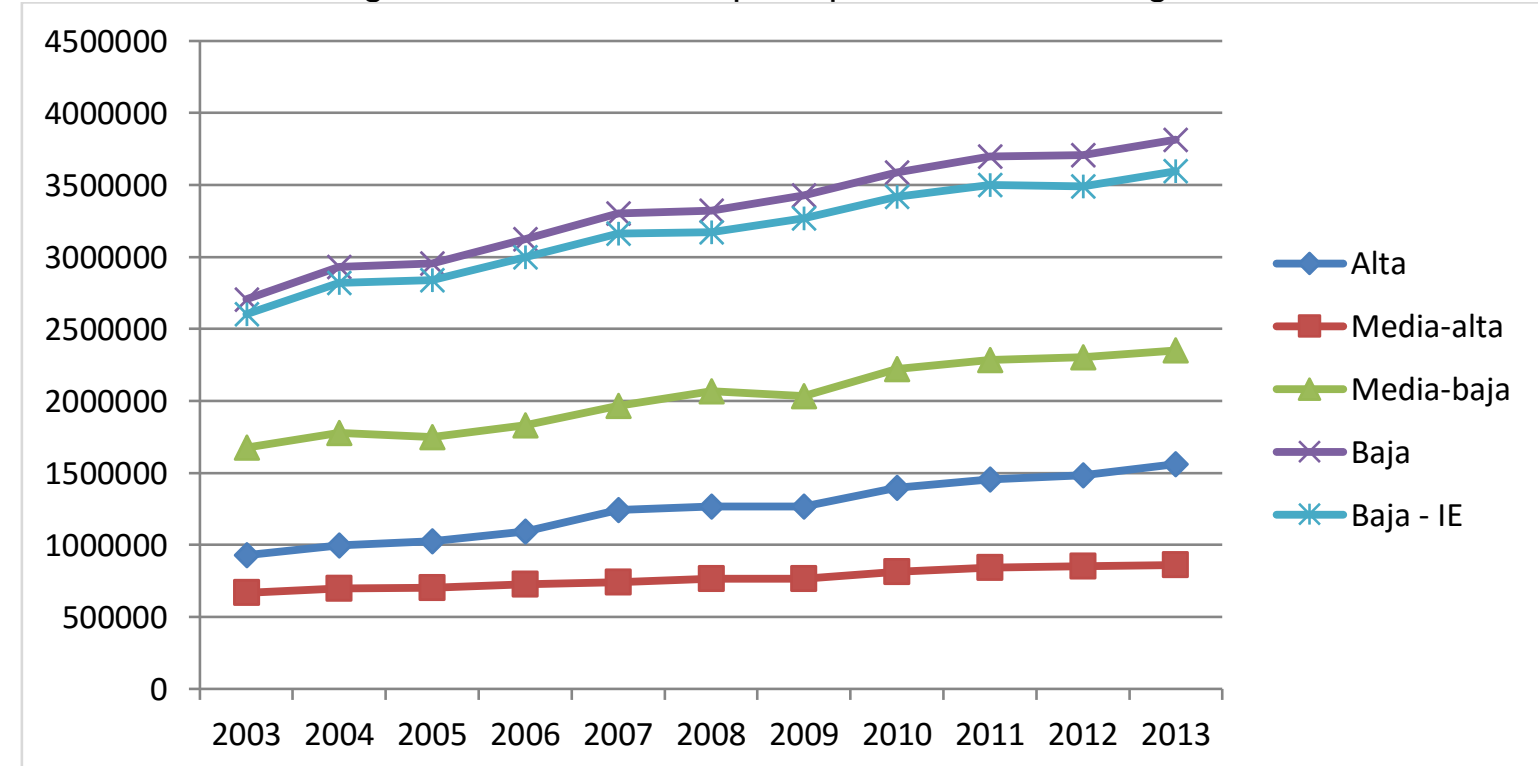

Fuentes: Elaboración propia a partir de IBGE.

${ }^{15}$ Los datos que se muestran a continuación corresponden a cada 31 de diciembre.

Papeles de Europa 
Orozco, Christian. ¿Reprimarización en la periferia?: El caso brasileño (2003-2013).

Observando la Figura 6 (para detalle, véase Tabla 1 del anexo) podemos evidenciar una clara tendencia creciente $(+3 \%$ anual acumulado) del número de empleados industriales. Los sectores que más empleo requieren son: los productos alimentarios y bebidas (un $21 \%$ del empleo industrial en 2006); la fabricación de prendas de vestir y accesorios (un 9\% en 2009); y, las máquinas y equipos (7\% en 2007). Sin embargo, las industrias que más crecen anualmente son: a) la extracción de petróleo y gas natural (17\%); b) el mantenimiento, reparación e instalación de maquinaria y equipo (13\%); y otros equipos de transporte (8\%).

Ahora bien, si desagregamos el sector de otros equipos de transporte, descubrimos que está compuesto por una serie de subsectores que presentan los niveles más altos de crecimiento de empleo, así, si bien entre 1996-2005 la construcción, montaje y reparación de aeronaves era el sector que más crecía anualmente $(13 \%)$, entre 1996-2013 es el sector de construcción y reparación de barcos el que lidera $(10 \%)^{16}$.

En cuanto al nivel tecnológico, los sectores de baja intensidad generan durante todo el periodo aproximadamente la mitad del todo el empleo de la industria, la tecnología media-baja representa una cuarta parte, y la otra cuarta parte se reparte entre los sectores de alta y media-alta tecnología. Finalmente, cabe destacar el significativo peso que las industrias extractivas han ido ganando en los últimos años en términos de generación de empleo, no olvidemos que ésta es la industria número uno en ritmo de crecimiento anual medio durante el periodo analizado.

En resumen:

a) el sector primario destruye durante el periodo tanto empleo en términos relativos como absolutos;

b) el sector industrial lo incrementa ligeramente (menos que los servicios), principalmente en sectores de baja tecnología como la extracción de petróleo y gas natural, pero también en actividades de alta, como la fabricación de aeronaves 0 barcos.

\subsection{Estructura comercial}

Puga (2006) plantea que el buen desempeño de las exportaciones brasileñas, sobre todo, a partir de 2001 -reflejado en el creciente grado de apertura- se ha visto deslucido porque, en general, el crecimiento de las exportaciones se ha producido sobre la base de un aumento sustancial de los precios de los productos exportados por el país. Así pues, dicha mejora se produce en los sectores intensivos en recursos naturales; mientras que, por otro lado, en otros sectores se estaría produciendo una sustitución de producción nacional por importaciones. Así pues, a lo largo de los siguientes apartados intentaremos contrastar esta afirmación.

Para ello, en base a la información de las tablas 1 y 2, comprobamos las siguientes características del comercio brasileño. En primer lugar, aunque entre 2003 y 2013 el comercio está cada vez más concentrado en los diez principales productos

\footnotetext{
${ }^{16}$ De hecho, Paz (2014) considera que el notable incremento del empleo en la industria naval está directamente relacionado con las particularidades de la explotación de petróleo en aguas profundas y la aplicación ciertas estrategias de industrialización basadas en los recursos.

Papeles de Europa

Vol. 29, Núm. 1 (2016): 51-81

http://dx.doi.org/10.5209/PADE.55011
} 
Orozco, Christian. ¿Reprimarización en la periferia?: El caso brasileño (2003-2013).

transables, el aumento en la concentración de las exportaciones es considerablemente mayor al de las importaciones. En segundo lugar, el patrón exportador está claramente guiado hacia los productos primarios, tanto la soja, como el mineral de hierro o la carne tienen una posición destacada; y por otra parte, aunque también nos encontramos con productos de media y alta tecnología -como los coches o las aeronaves- entendemos que son, sobre todo, fruto del ensamblaje de piezas importadas. En cuanto a las principales importaciones que arriban al país, nos encontramos una mayor heterogeneidad de productos, tanto industriales como turborreactores y circuitos integrados, como primarios como trigo, malta, y especialmente crudo de petróleo.

Tabla 1. Top de exportaciones brasileñas al mundo por producto

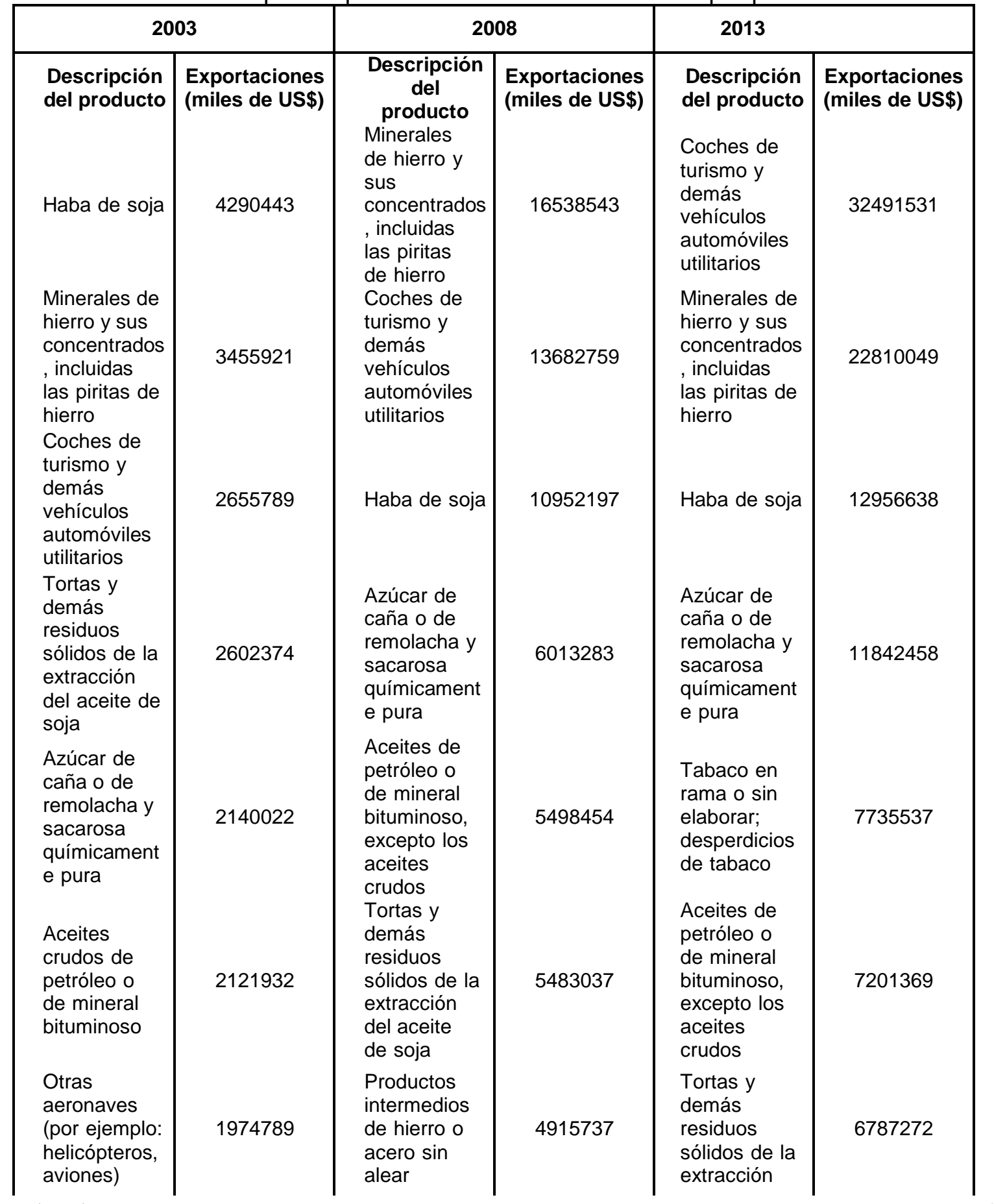

Papeles de Europa

Vol. 29, Núm. 1 (2016): 51-81 
Orozco, Christian. ¿Reprimarización en la periferia?: El caso brasileño (2003-2013).

\begin{tabular}{|c|c|c|c|c|c|}
\hline & & & & $\begin{array}{l}\text { del aceite de } \\
\text { soja }\end{array}$ & \\
\hline $\begin{array}{l}\text { Carne y } \\
\text { despojos } \\
\text { comestibles } \\
\text { frescos, } \\
\text { refrigerados } \\
\text { o congelados }\end{array}$ & 1862136 & $\begin{array}{l}\text { Café, } \\
\text { incluso } \\
\text { tostado o } \\
\text { descafeinado } \\
\text {; cascara y } \\
\text { cascarilla de } \\
\text { café }\end{array}$ & 4826745 & $\begin{array}{l}\text { Madera } \\
\text { aserrada o } \\
\text { desbastada, } \\
\text { cortada o } \\
\text { desenrollada }\end{array}$ & 6307631 \\
\hline $\begin{array}{l}\text { Pasta } \\
\text { química de } \\
\text { madera a la } \\
\text { sosa (soda) } \\
\text { o al sulfato }\end{array}$ & 1692088 & $\begin{array}{l}\text { Madera } \\
\text { aserrada o } \\
\text { desbastada, } \\
\text { cortada o } \\
\text { desenrollada }\end{array}$ & 4785443 & $\begin{array}{l}\text { Carne y } \\
\text { despojos } \\
\text { comestibles } \\
\text { frescos, } \\
\text { refrigerados } \\
\text { o conqelados }\end{array}$ & 5484727 \\
\hline $\begin{array}{l}\text { Aceites de } \\
\text { petróleo o } \\
\text { de mineral } \\
\text { bituminoso, } \\
\text { excepto los } \\
\text { aceites } \\
\text { crudos } \\
\end{array}$ & 1599765 & $\begin{array}{l}\text { Aceites } \\
\text { crudos de } \\
\text { petróleo o } \\
\text { de mineral } \\
\text { bituminoso }\end{array}$ & 4363523 & $\begin{array}{l}\text { Jugos de } \\
\text { frutas u } \\
\text { otros frutos } \\
\text { (incluido el } \\
\text { mosto de } \\
\text { uva) o de } \\
\text { hortalizas } \\
\end{array}$ & 4837830 \\
\hline \multicolumn{2}{|c|}{$\begin{array}{l}\text { Total de las } 10 \text { exportaciones } \\
\text { principales }\end{array}$} & \multicolumn{2}{|c|}{$\begin{array}{l}\text { Total de las } 10 \text { exportaciones } \\
\text { principales }\end{array}$} & \multicolumn{2}{|c|}{$\begin{array}{l}\text { Total de las } 10 \text { exportaciones } \\
\text { principales }\end{array}$} \\
\hline \multicolumn{2}{|l|}{24395259} & \multicolumn{2}{|l|}{77059721} & \multicolumn{2}{|l|}{118455042} \\
\hline \multicolumn{2}{|c|}{$\begin{array}{l}\text { Total exportaciones } \\
73203222\end{array}$} & \multicolumn{2}{|c|}{$\begin{array}{l}\text { Total exportaciones } \\
197942443\end{array}$} & \multicolumn{2}{|c|}{$\begin{array}{l}\text { Total exportaciones } \\
242178054\end{array}$} \\
\hline \multicolumn{2}{|c|}{ Como \% del total 33,33} & \multicolumn{2}{|c|}{ Como \% del total 38,93 } & \multicolumn{2}{|c|}{ Como $\%$ del total 48,91} \\
\hline
\end{tabular}

Fuente: Elaboración propia a partir de Trade Map

Tabla 2. Top de importaciones del mundo a Brasil por producto

\begin{tabular}{|c|c|c|c|c|c|}
\hline \multicolumn{2}{|c|}{2003} & \multicolumn{2}{|c|}{2008} & \multicolumn{2}{|l|}{2013} \\
\hline $\begin{array}{c}\text { Descripción } \\
\text { del } \\
\text { producto }\end{array}$ & $\begin{array}{l}\text { Exportaciones } \\
\text { (miles de US\$) }\end{array}$ & $\begin{array}{l}\text { Descripción } \\
\text { del producto }\end{array}$ & $\begin{array}{l}\text { Exportaciones } \\
\text { (miles de US\$) }\end{array}$ & $\begin{array}{l}\text { Descripción } \\
\text { del producto }\end{array}$ & $\begin{array}{l}\text { Exportaciones } \\
\text { (miles de US\$) }\end{array}$ \\
\hline $\begin{array}{l}\text { Aceites } \\
\text { crudos de } \\
\text { petróleo o } \\
\text { de mineral } \\
\text { bituminoso }\end{array}$ & 3801623 & $\begin{array}{l}\text { Pieles y } \\
\text { demás } \\
\text { partes de } \\
\text { aves con sus } \\
\text { plumas o } \\
\text { llumón }\end{array}$ & 16574403 & $\begin{array}{l}\text { Papel del } \\
\text { tipo utilizado } \\
\text { para papel } \\
\text { higiénico y } \\
\text { toallitas para }\end{array}$ & 17756951 \\
\hline $\begin{array}{l}\text { Aceites de } \\
\text { petróleo o de } \\
\text { mineral } \\
\text { bituminoso, } \\
\text { excepto los } \\
\text { aceites } \\
\text { crudos }\end{array}$ & 1815667 & $\begin{array}{l}\text { Antimonio y } \\
\text { sus } \\
\text { manufactu- } \\
\text { ras, incluidos } \\
\text { los } \\
\text { desperdicios } \\
\text { y desechos }\end{array}$ & 9689658 & $\begin{array}{l}\text { Diamantes, } \\
\text { incluso } \\
\text { trabajados, } \\
\text { sin montar ni } \\
\text { engarzar }\end{array}$ & 16319993 \\
\hline $\begin{array}{l}\text { Partes y } \\
\text { accesorios } \\
\text { de vehículos } \\
\text { automóviles }\end{array}$ & 1500784 & $\begin{array}{l}\text { Fosfatos de } \\
\text { calcio } \\
\text { naturales y } \\
\text { fosfatos } \\
\text { aluminocálci- } \\
\text { cos naturales }\end{array}$ & 5342624 & $\begin{array}{l}\text { Malta (de } \\
\text { cebada u } \\
\text { otros } \\
\text { cereales), } \\
\text { incluso } \\
\text { tostada }\end{array}$ & 9081176 \\
\hline $\begin{array}{l}\text { Circuitos- } \\
\text { integrados y } \\
\text { microestructu }\end{array}$ & 1470539 & $\begin{array}{l}\text { Hullas; } \\
\text { briquetas, } \\
\text { ovoides y }\end{array}$ & 4982138 & $\begin{array}{l}\text { Turborreacto- } \\
\text { res, } \\
\text { turbopropulso }\end{array}$ & 8296706 \\
\hline
\end{tabular}

Papeles de Europa 
Orozco, Christian. ¿Reprimarización en la periferia?: El caso brasileño (2003-2013).

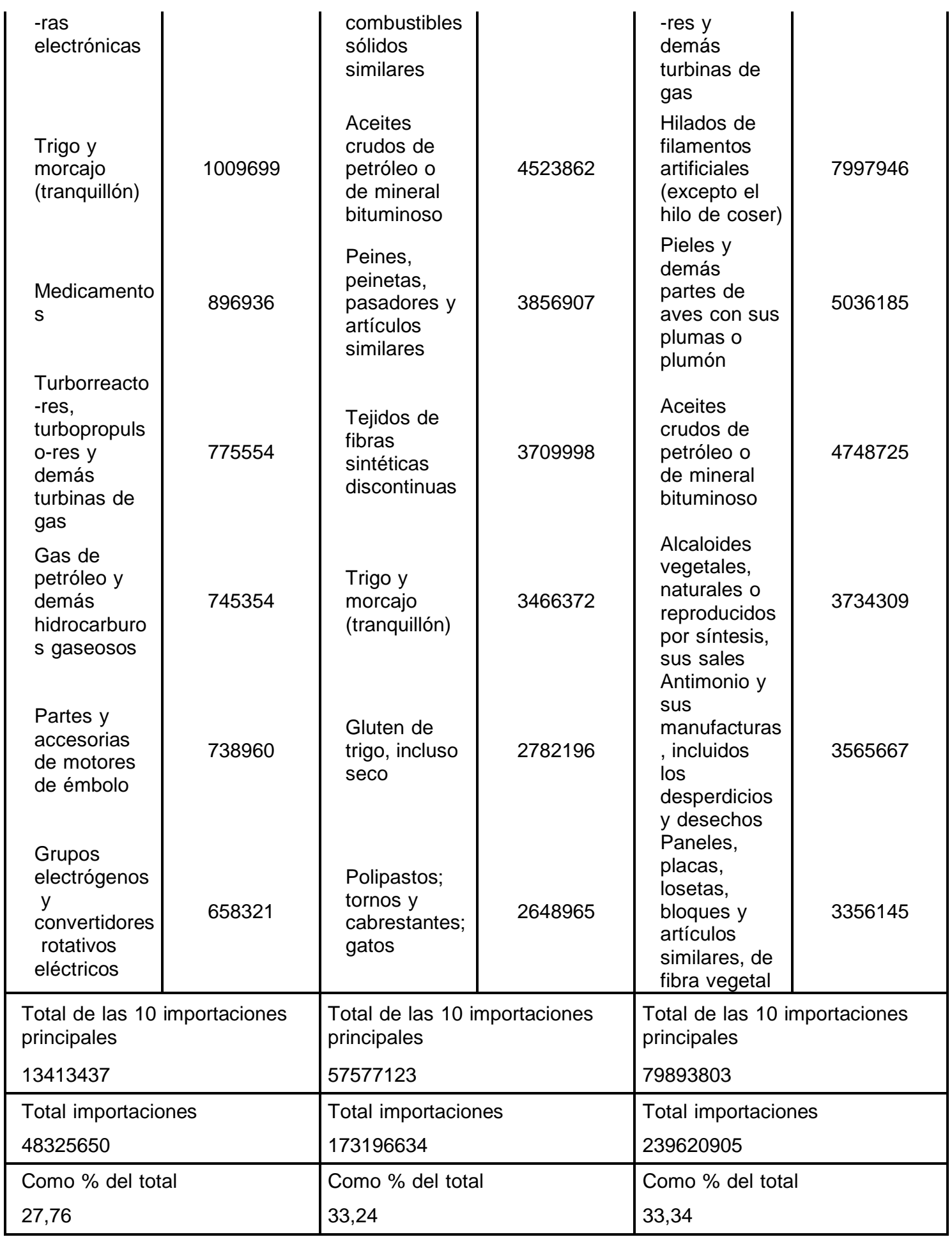

Fuente: Elaboración propia a partir de Trade Map.

Ahora, tomando como año base 2002 distinguimos del total del valor de la exportación de un producto la parte que se explica por el aumento de la cantidad exportada de la parte que corresponde a un aumento del precio de la commodity.

Así pues, la Figura 7, nos muestra claramente que los ingresos de las exportaciones primarias se explican cada vez más por la subida de los precios internacionales de los productos primarios, y dentro de éstos, son los productos mineral-extractivos los que más han experimentado un aumento del nivel de precios. Así, en 2013 mientras

Papeles de Europa 
Orozco, Christian. ¿Reprimarización en la periferia?: El caso brasileño (2003-2013).

que los ingresos por las exportaciones de haba de soja por cantidad representan un $35,6 \%$, el mineral de hierro y sus concentrados solo supone un $18,6 \%$, el $81,4 \%$ restante se explica por aumentos en los niveles de precios.

Figura 7. Participación del precio y la cantidad del top de productos primarios exportados

(Año base 2002)
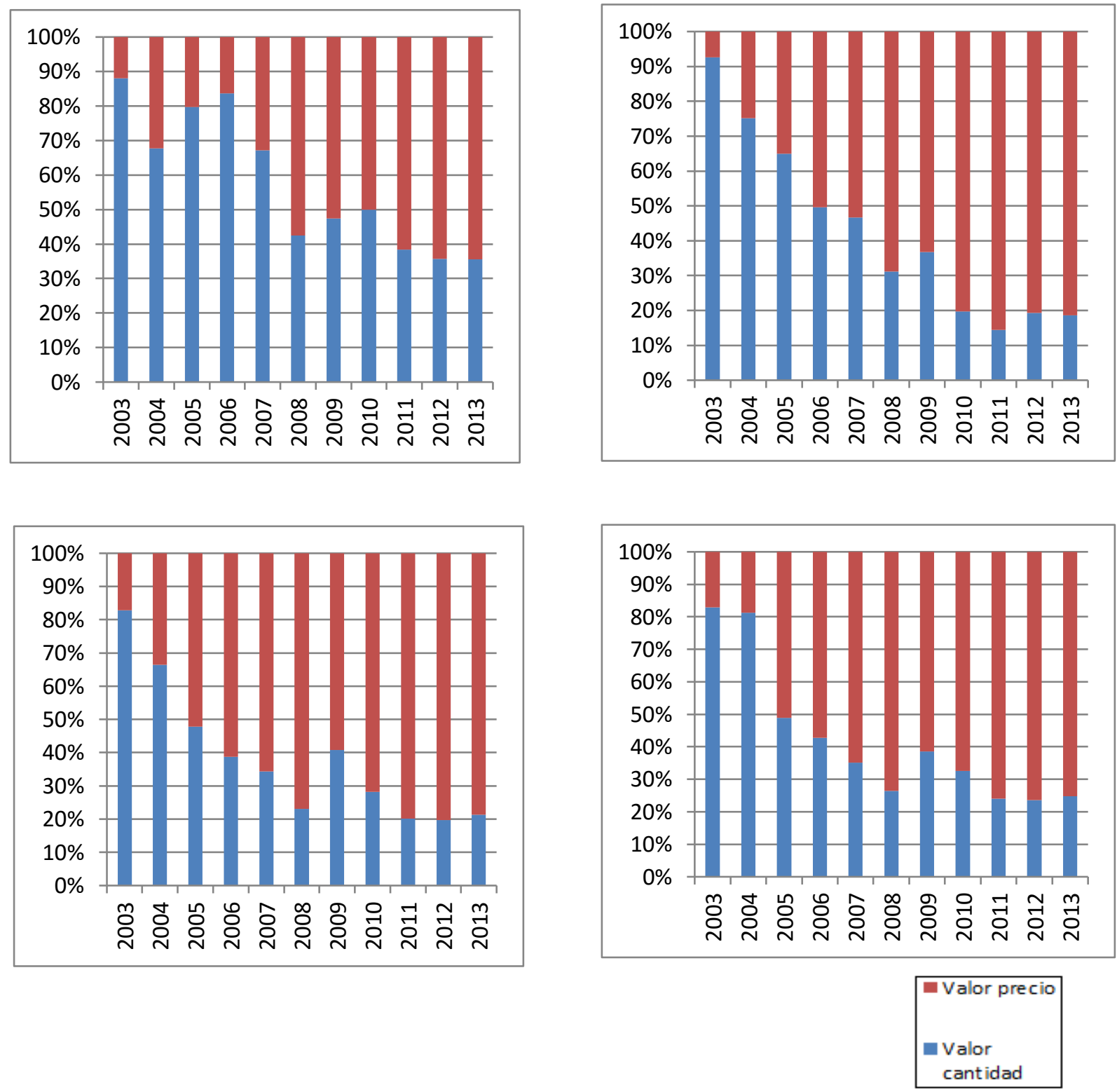

Nota: arriba-derecha: haba de soja; arriba-izquierda: minerales de hierro y sus concentrados, incluidas las piritas de hierro; abajo-derecha: aceites crudos de petróleo o de mineral bituminoso; abajo-izquierda: aceites de petróleo o de mineral bituminoso, excepto los aceites crudos

Fuente: Elaboración propia a partir de Un Trade Basedate.

Adicionalmente, el análisis de la evolución del comercio brasileño por niveles tecnológicos solamente refuerza lo ya planteado hasta ahora, el peso relativo de las exportaciones primarias es el único que es cada vez mayor, todos los demás o caen o se estancan. En cuanto a las importaciones, no apreciamos grandes cambios. 
Orozco, Christian. ¿Reprimarización en la periferia?: El caso brasileño (2003-2013).

Para terminar este apartado, estudiaremos la evolución de los coeficientes de apertura (CA) y penetración (CP). EI CA de las exportaciones (exportaciones/PIB) es un indicador que nos permite ver si la producción está siendo dirigida fundamentalmente al mercado interno -bajo coeficiente- o al mercado externo -alto coeficiente. En el caso del CA, observamos una tendencia decreciente tanto general (GEN) como, sobre todo, de la industria de transformación (IND.TRN); por el contario, el CA de las industrias extractivas (IND.EXT) crece un 10\% de 2003 hasta 2013 (recordemos que en 1996 su CA-IND.EXT era de un 35,6\%).

En el caso del CP de las importaciones (importaciones/consumo doméstico aparente ${ }^{17}$ ) observamos una tendencia creciente, es decir, la proporción de consumo doméstico que se importa es tendencialmente mayor. Atendiendo a la Tabla 3, al igual que antes, podemos distinguir comportamientos diferentes, mientras que el CPGEN y el CP-IND.TRN crecen, el CP-IND.EXT fluctúa más, así, si en 2003 era un $47,5 \%$, en 2008 alcanza un pico del 67,8\%, para retroceder en los años posteriores.

Tabla 3. Coeficientes de apertura (CA) y penetración (CP) comercial general (GEN), de las industrias de transformación (IND.TRN) y de las industrias extractivas (IND.EXT) en \%

\begin{tabular}{|c|c|c|c|c|c|c|}
\hline Año & CA-GEN & CA-IND.TRN & CA-IND.EXT & CP-GEN & CP-IND.TRN & CP-IND.EXT \\
\hline 2003 & 21,8 & 20,5 & 50,9 & 16,6 & 15,2 & 47,5 \\
2004 & 22,9 & 21,6 & 52,2 & 17,4 & 15,5 & 54,9 \\
2005 & 22,4 & 20,8 & 53,8 & 16,3 & 14,5 & 49,9 \\
2006 & 22 & 19,9 & 60,3 & 16,7 & 14,9 & 54,5 \\
2007 & 17 & 15,3 & 55,9 & 20,1 & 18 & 61,7 \\
2008 & 19 & 17 & 61 & 19,5 & 16,8 & 67,8 \\
2009 & 16,6 & 15,3 & 47,7 & 17,3 & 14,9 & 61 \\
2010 & 17,5 & 13,6 & 72,4 & 17,5 & 16,3 & 49,6 \\
2011 & 18,7 & 14,1 & 75,4 & 18,7 & 17,4 & 52,2 \\
2012 & 19 & 15,1 & 68,2 & 20 & 18,7 & 47,8 \\
2013 & 18,5 & 15,1 & 60,7 & 20,9 & 19,5 & 46,4 \\
\hline
\end{tabular}

Fuente: Elaboración propia a partir de Ipedata y Funcex.

A raíz del análisis de los indicadores de este bloque planteamos que:

a) el patrón exportador brasileño tiene un marcado sesgo hacia productos primarios, de forma muy destacada hacia la soja y el hierro; y a pesar de que la partida de automóviles de turismo y demás vehículos automóviles utilitarios (alta tecnología) ocupa todos los años analizados una posición destacada, entendemos que se trata principalmente de actividades de ensamblaje ya que por el lado de las importaciones la partida de partes y accesorios de vehículos automóviles tiene también una presencia significativa;

b) el crecimiento de los ingresos por exportaciones se explica fundamentalmente por el destacado crecimiento tanto relativo como absoluto de los bienes primarios, hasta 2008 liderado por productos mineral-extractivos (cada vez más abierto hacia el exterior), y más adelante por productos agropecuarios;

${ }^{17}$ Consumo doméstico aparente $=$ producción doméstica + importaciones - exportaciones .

Papeles de Europa 
Orozco, Christian. ¿Reprimarización en la periferia?: El caso brasileño (2003-2013).

c) el incremento del valor de las exportaciones no solo se debe al aumento de la cantidad de productos comercializados, sino que el crecimiento de los niveles de los precios de las commodities también juega un papel crecientemente protagónico, mayor en el caso de productos mineral-extractivos que agropecuarios.

\subsection{Aspectos monetarios y cambiarios}

En cuanto a la evolución del tipo de cambio efectivo, detectamos distintas fases. Hasta 2003 el real brasileño se mantiene devaluado; entre 2003 y 2011 la moneda experimenta una considerable apreciación; y, a partir de 2011 el tipo de cambio se invierte nuevamente, es decir, el real brasileño se deprecia.

Dos son las explicaciones que la literatura considera fundamentales para explicar la tendencia a la apreciación del tipo de cambio del real brasileño. La primera está asociada a los efectos de la enfermedad holandesa, así, cuando el precio de los productos primarios crece, la exportación de este tipo de productos genera un excedente de divisas para el país en cuestión. Si el precio de la moneda nacional no se estabiliza a través de medidas de esterilización, la moneda tiende a apreciarse, modificando los precios relativos entre los bienes transables y no transables. Las exportaciones (diferentes a los productos primarios) se vuelven menos competitivas mientras que el precio de los bienes importados tiende a caer. Los bienes no transables se benefician de los precios relativos, ya que están protegidos de forma "natural" de la competencia extranjera, y se convierten en objeto de especulación (Ros, 2011). La segunda explicación está relacionada con la magnitud de los flujos de capital, atraídos por la diferencia, muy marcada, en los tipos de interés ${ }^{18}$, por las oportunidades para realizar operaciones de carry trade y por el tamaño del mercado interno. Así pues, durante este periodo se aprecia un destacado aumento de las inversiones directas y en cartera (Salama, 2012: 244). Y dado que la balanza por cuenta corriente es ligeramente negativa durante la mayor parte de este periodo ${ }^{19}$, entendemos que la apreciación del real brasileño se debe principalmente a la segunda explicación.

\footnotetext{
${ }^{18}$ La apreciación de la moneda entre 2002 y 2008 frente al dólar es especialmente intensa en las economías que han adoptado la regla de Taylor para controlar la inflación mediante la política monetaria -alza de los tipos de interés determinado independientemente de sus efectos sobre el empleo, el crecimiento y la deuda pública interna- y cambiaria de inspiración monetarista, es decir, subordinación de las políticas de tipo de cambio a la meta de inflación). Como apuntó Ros (2011), la sensibilidad del alza de las tasas de interés es baja debido al crédito débil, por lo que la eficacia de esta política requiere que el aumento de la tasa sea muy alto, lo que atraerá capital extranjero y fomentará una apreciación de la moneda nacional frente al dólar.

${ }^{19} \mathrm{http}$ ://datos.bancomundial.org/indicator/BN.CAB.XOKA.CD?end=2013\&locations=BR\&start=2003

Papeles de Europa 
Orozco, Christian. ¿Reprimarización en la periferia?: El caso brasileño (2003-2013).

Figura 8. Tipo de cambio real efectivo 1996-2013 (Índice 2005=100)

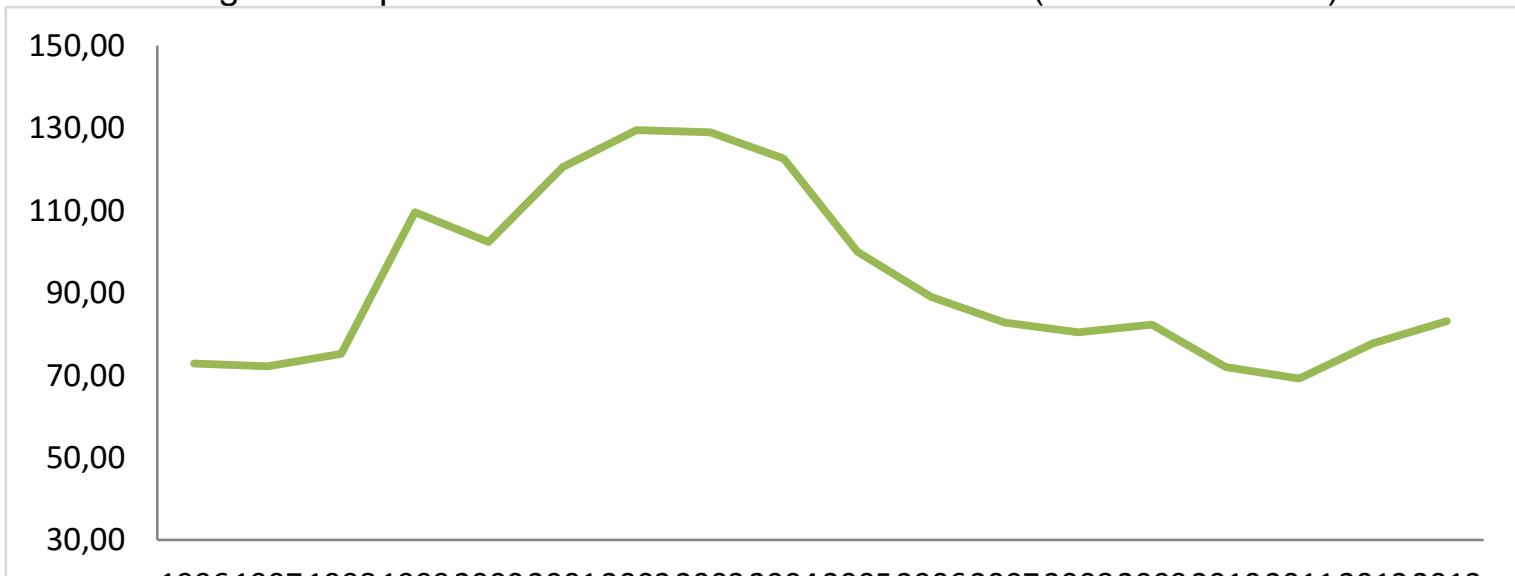

199619971998199920002001200220032004200520062007200820092010201120122013

Nota: una tendencia a la baja significa una apreciación de la moneda. El tipo de cambio se expresa en términos reales, para reflejar los diferenciales de inflación.

Fuente: Elaboración propia a partir de la CEPAL.

Desde el año 2003, la economía brasileña está experimentando una apreciación considerable de su moneda respecto al dólar y al renminbi. La apreciación del tipo de cambio favorece las importaciones y sustituyen parcialmente la producción local. En este sentido, las industrias más intensivas en capital y las que más importan insumos (bienes de capital y bienes intermedios) son las más favorecidas puesto que las importaciones se abaratan, especialmente las price marker como la industria aeronáutica. En sentido contrario, aquellas industrias más intensivas en fuerza de trabajo y que utilizan principalmente insumos locales se ven perjudicadas, sobre todo si son price-taker como la industria textil, a menos que estén protegidas por la falta de competencia extranjera, la industria de la madera es un buen ejemplo de ello (Salama, 2012: 245). Por tanto, en conjunto podemos señalar que la apreciación del real entre 2003-2011 generó tendencias contradictorias, puesto que, si bien benefició a nivel interno a industrias de alto nivel tecnológico y perjudicó a las de baja, a nivel externo, constituyó un factor negativo en la competitividad de las exportaciones brasileñas, principalmente industriales.

\section{CONCLUSIONES}

Para poder responder a la pregunta de invetigación: "¿entre el periodo 2003-2013 se ha producido o no un proceso de reprimarización de la economía de Brasil?" en primer lugar nos hemos introducido en el debate sobre la forma en que distintas corrientes conceptualizan el fenómeno de la reprimarización, y comprobar que si bien comparte ciertos rasgos con los procesos de desindustrialización y enfermedad holandesa, éstos son dos fenómenos diferenciados. Así pues, la forma en como conceptualizamos el fenómeno de la reprimarización hizo necesario, a continuación, profundizar sobre los rasgos historicos-estructurales más destacados de los procesos de industrialización y desindustrialización brasileños, procesos que hemos caracterizado como periféricos-dependientes. A continuación, se ha estudiado una serie de indicadores considerados fundamentales para poder arrojar luz sobre la pregunta inicial, de su análisis hemos llegado a la siguiente síntesis:

- Participación sectorial del PIB y contenido local. Por una parte, en términos relativos durante el periodo de estudio el sector vinculado a los recursos naturales experimenta un tímido crecimiento, el sector servicios gana un peso Papeles de Europa 
Orozco, Christian. ¿Reprimarización en la periferia?: El caso brasileño (2003-2013).

sustancial en el PIB brasileño, y la industria (no extractiva) se deprime. Y, por otra parte, aunque son los productos de baja tecnología los que más peso ganan en contenido nacional, también experimentan cierto crecimiento de este contenido los bienes de media-alta y alta tecnología, especialmente a partir de 2005.

- Población ocupada por sectores. Si bien la población empleada en sectores vinculados a los recursos naturales cae notablemente pese al crecimiento del empleo extractivo industrial tanto en términos relativos como absolutos, los sectores secundario y terciario, especialmente este último, generan empleo. Ahora bien, si observamos el empleo industrial que se crea, tenemos que: el aumento de la población ocupada en sectores de baja intensidad tecnológica representan casi la mitad de la generación del empleo total en la industria, y a la vez, un sector de alto nivel tecnológico como es el sector de construcción y reparación de barcos también lidera la creación de empleo hasta 2013.

- Estructura comercial. Aunque el sesgo exportador brasileño está claramente guiado por las materias primas (debido en gran medida al aumento de sus precios internacionales), existen algunos sectores de alta tecnología como el sector de los coches de turismo y utilitarios (alta tecnología) que aumentan su cuota exportadora considerablemente.

- Aspectos monetarios y cambiarios. Por una parte, entendemos que la apreciacion del real brasileño a partir de 2003 no se debe fundamentalmente a una entrada de divisas procedentes de la exportación de materias primas, si no se debe más bien a operaciones inversoras y especulativas. Por otra parte, dicha apreciación durante la mayor parte del periodo de estudio, como ya hemos señalado antes, genera efectos contradictorios.

En base a lo hasta ahora expuesto podemos plantear dos consideraciones finales. Primera, no se puede afirmar taxativamente que la economía brasileña experimente un proceso de reprimarización durante el periodo de análisis, a nivel interno no ha habido un marcado cambio estructural hacia sectores vinculados a los recursos naturales, y a nivel externo, si bien las exportaciones primarias han crecido considerablemente, la exportación de coches de turismo y utilitarios, por ejemplo, se convirtió en 2013 en el principal producto de exportación en términos de ingresos por exportaciones. Segunda, el destacado protagonismo que el sector terciario ha ido ganando en los distintos ámbitos de la estructura productiva -reflejado en los indicadores analizados- nos conduce a pensar que el fenómeno de la terciarización se está manifestando en Brasil.

Para terminar, cabe señalar como futuras líneas de investigación:

i) valorar hasta que punto la aplicación de políticas industriales por parte del gobierno brasileño presidido por el Partido de los Trabajadores ha generado dinámicas virtuosas sobre la industria;

ii) encontrar ciertos nexos de unión que en ocaciones surgen entre sectores de baja intensidad tecnológica y alta, por ejemplo, la industria extractiva y el sector de la construcción y reparación de plataformas petrolíferas y/o gasistas. 
Orozco, Christian. ¿Reprimarización en la periferia?: El caso brasileño (2003-2013).

\section{BIBLIOGRAFÍA}

Álvarez, N. (2009): Ajustes y salarios. Las consecuencias del neoliberalismo en América Latina y Estados Unidos, Fondo de Cultura Económica, Madrid.

Alves, C., Aparecida, S., y Lemes, K. (2008): "O Sentido da Reprimarização da Pauta Exportadora: uma interpretação à luz de Celso Furtado", Caio Prado Jr. e Francisco de Oliveira, SOBER.

Arrighi, G., Hopkins, T., y Wallerstein, I. (1999): Movimientos Antisistémicos, Akal, Madrid.

Arrighi, G., Silver, B., y Brewer, B. (2003): "Industrial Convergence, Globalization, and the Persistence of the North-South Divide", Studies in Comparative International Development, vol. 38, n. 91 , pp. 3-31.

Arrighi, G., y Drangel, J. (1986): "The Stratification of the World-Economy: An Exploration of the Semiperipherial Zone", Review, vol. 10, n. ํ 1, pp.9-74.

Baumol, W. (1967): "Macroeconomics of unbalanced growth: The anatomy of urban crisis", The American Economic Review, vol. 57, n. ํ 3, pp. 415-426.

Baumol, W. (2000): "Services as leaders \& the leader of the services. Inaugural lecture", International Conference on the Economics \& Socio-Economics of Services, junio 22-23, Lille.

Baumol, W., y. Bowen, W. (1966): Performing Arts, The Economic Dilemma: a study of problems common to theater, opera, music, and dance, Twentieth Century Fund, New York.

Begué, A. (2001): El Papel Económico del Estado y las Políticas de Privatización en el Brasil de los Años Noventa, Tesis Doctoral, Facultad de Ciencias Económicas y Empresariales, UCM, Madrid.

Bruno, M., y J. Sachs. (1982): "Energy and resource allocation: a dynamic model of the Dutch disease", Review of Economic Studies, vol. 49, n. $⒌$

Buiter, W., y D. Purvis, Oil. (1980): "Disinflation, and export competitiveness: a model of the Dutch disease", National Bureau of Economic Research (NBER), Working Paper Series, n. ํ 5592.

Cano, W. (2007): "Raízes da Concentração Industrial em São Paulo", Ed. IE/Unicamp.

Carcanholo, M. (2010): "Inserção externa e vulnerabilidade da Economia brasileira no governo Lula", Garamond, pp. 109-131.

Carcanholo, M. (2014): "Desafios e Perspectivas para a América Latina do Século XXI”, Argumentum, vol. 6, n. ㅇ 2, pp. 6-24.

Clark, C, (1940): The conditions of economic progress, Mcmillan, London.

Cohen, S., y Zysman, J. (1987): Manufacturing Matters: The Myth of the PostIndustrial Economy, Basic Books, New York.

Corden, W., y Neary, J. (1982): "Booming sector and de-industrialisation in a small open economy", Economic Journal, vol. 92, pp. 825-84.

Dasgupta, S., y Singh, A. (2006): "Manufacturing, services and premature deindustrialization in developing countries - a Kaldorian analysis", World Institute for Development Economics Research, n. ㅇ 49.

Davis, G. (1995): "Learning to Love the Dutch Disease: Evidence from the Mineral Economies”, World Development, vol. 23, n. ㅇ 10, pp. 1765-1779.

Evans, P. (1979): Dependent Development: The Alliance of Multinational, State, and Local Capital in Brazil, Princeton University Press.

Fajnzylber, F. (1983): La industrialización trunca de América Latina, Nueva Imagen, México.

Papeles de Europa 
Orozco, Christian. ¿Reprimarización en la periferia?: El caso brasileño (2003-2013).

Fajnzylber, F., y Martínez, T. (1976): Las empresas trasnacionales. Expansión a nivel mundial y proyección en la industria mexicana, Fondo de Cultura Económica, México.

Ferreira, D., y Cutrim, A. (2011): "Desindustrialização e reprimarização da economia brasileira contemporânea num contexto de crise financeira global: conceitos e evidencias”, Revista Economia Ensaios, vol. 26, n. ำ 1, pp. 35-64.

Fontagné, L., y Lorenzi, J. (2005): Désindustrialisation, délocalisations, Conseil d'Analyse Économique, Paris.

Forbes, 11 de abril de 1983, pp. 146-149.

Gonçalves, R. (2011): "Nacional-desenvolvimentismo às Avessas", IPEA, N. ㄴ4.

Grigera, J. (2011): "La desindustrialización en Argentina. ¿Agresión a la manufactura o reestructuración capitalista?”, Ediciones Continente, pp. 81-101, Buenos Aires.

Grigera, J. (2012): "El concepto de desindustrialización como peculiaridad argentina”, Revista de Estudios Marítimos y Sociales, n. 5/6, Mar del Plata.

Gylfason, T., y Nguessa, J. (2014): "Diversification, Dutch Disease, and Economic Growth: Options for Uganda", Center of Economic Estudies \& Ifo Institute Working Paper, n. ㅇ 5095.

IBGE. Pesquisa Industrial Anual - Empresa. In: Série Relatórios Metodológicos do IBGE, vol. 26, 2004.

Kaldor, N. (1966): Causes of the Slow Rate of Growth in the UK. Cambridge University Press, London.

Kaldor, N. (1967): Problems of industrialization in underdeveloped countries. Strategic Factors of Economic Development, Cornell University Press, New York.

Kohli, A. (2004): State-Directed Development. Political Power and Industrialization in the Global Periphery, Cambridge University Press.

Maroto, A. (2013): "Las relaciones entre servicios y productividad: Un tema a impulsar en el ámbito regional y territorial”, Investigaciones Regionales, n. ำ 27, pp. 157-183, Madrid.

Márquez, L., y Pradilla, E. (2008): “Desindustrialización, terciarización y estructura metropolitana: un debate conceptual necesario", Tercera Época, n. ㅇ 69, pp. 21-45.

Martínez, J, (2010): "La estructura teórica Centro/Periferia y el análisis del Sistema Económico Global: ¿obsoleta o necesaria?", Reunión Internacional de Economía Mundial.

Medialdea, B. (2009): Subdesarrollo, Capital Extranjero y Financiarización: La Trampa Financiera de la Economía Brasileña, Tesis Doctoral, Universidad Complutense de Madrid, Madrid.

Messenberg, R. (2012): "Desindustrialização no Brasil: Apontamentos para um Debate em Favor do Desenvolvimento Econômico", Ipea Conjuntura em Foco, n. $\stackrel{18 .}{18}$

Nadal, A. (2009): "La reprimarización de América Latina”, La Jornada, 07/10/2009.

O’Donnel, G. (1977): Apuntes para una teoría del Estado, Cedes, Buenos Aires.

Palma, G. (2005): "Quatro fontes de desindustrialização e um novo conceito de doença holandesa", Conferência de industrialização, desindustrialização e desenvolvimento, FIIESP.

Pasinetti, L. (1981): Cambio estructural y crecimiento económico. Pirámide, Madrid.

Paz, M. (2014): "Oil and development in Brazil: Between an extractive and an industrialization strategy", Energy Policy, n. ำ 73, pp. 505-511, Madrid.

Papeles de Europa

Vol. 29, Núm. 1 (2016): 51-81

http://dx.doi.org/10.5209/PADE.55011 
Orozco, Christian. ¿Reprimarización en la periferia?: El caso brasileño (2003-2013).

Pereira, D. (2012): "A desindustrialização em marcha no Brasil: uma análise comparada", XVII Encontro Nacional de Economia Política - ENEP/SEP, vol.1, pp. 1-22, Rio de Janeiro.

Pereira, D. (2015): Desindustrialização e Estruturas Produtivas Regionais no Brasil, Tesis Doctoral, Instituto de Economia da Universidade Estadual, Campinas.

Puga, F. (2006): "Por que crescem as exportações", BNDES, n. ำ1, Brasília.

Ramírez, J. (2014): "Has Bolivia's 2006-12 gas policy been useful to combat the resource curse?", Resources Policy, n. ํ 41, pp. 113-123.

Ros, J. (2011): "How to neutralize the adverse developmental effects of the Dutch Disease", New Developmentalism and a Structuralist Development Macroeconomics, San Pablo.

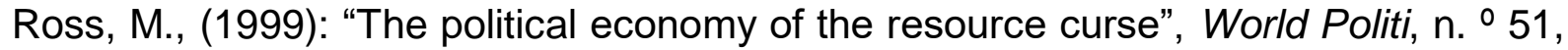
pp. 297-322.

Rowthorn, R., y Rawaswamy, R. (1997): "Deindustrialization: Causes and Implications", IMF working paper, n. WP/97/42, Oxford.

Rowthorn, R., y Rawaswamy, R. (1998): "Growth trade and deindustrialization", IMF working paper, n. ${ }^{\circ}$ WP/98/60, Oxford.

Sachs, J. y Warner, A. (2001): "The curse of natural resources", European Economic

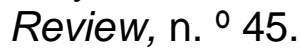

Sachs, J., y Warner, A. (1995): "Natural resource abundance and economic growth", National Bureau of Economic Research Working paper, n. ํ 5398, Cambridge

Salama, P. (2012): "China-Brasil: Industrialización y 'Desindustrialización Temprana”, Cuadernos de Economía, vol. 31, n. ํ 56, pp. 223-252, Bogotá.

Silva, J. (2014): "En torno a la discusión sobre 'desindustrialización". Un sucinto análisis respecto a la producción bruta y el producto interior bruto. Tendencias, vol. 15, n. ำ 1, pp. 109-130, Nariño.

Slipak, A. (2014): "La expansión de China en América Latina: incidencia en los vínculos comerciales argentino-brasileños", Congreso de Economía Política Internacional, Moreno.

Slipak, A., y Bolinaga, L. (2015): "El Consenso de Beijing y la reprimarización productiva de América Latina: el caso argentino", Problemas del Desarrollo, vol. 46, n. 183, pp.33-58, México D.F.

Sotelo, A. (2004): Desindustrialización y crisis del neoliberalismo, Plaza y Valdés, México D.F.

Taïeb, E., y Barros, O. (1989): Économie et société brésiliennes, Nathan, Paris.

The Economist, The Dutch disease, The Economist, 26 de noviembre, 1977, pp. 8283. 
Orozco, Christian. ¿Reprimarización en la periferia?: El caso brasileño (2003-2013).

\section{ANEXO}

Tabla 1. Clasificación de los sectores industriales por niveles tecnológicos

\begin{tabular}{|c|c|c|}
\hline Nivel tecnológico & Sector & CNAE* $^{*}$ \\
\hline Alta tecnología & $\begin{array}{l}\text { Otros equipos de transporte } \\
\text { Equipos médicos e instrumentos de hospital, } \\
\text { instrumentos de precisión y equipos ópticos para } \\
\text { automatización industrial, cronómetros y relojes } \\
\text { Máquinas, aparatos y equipos } \\
\text { Dispositivos electrónicos, material y equipos de } \\
\text { comunicación } \\
\text { Máquinas de oficina y equipos informáticos } \\
\text { Máquinas y equipos } \\
\text { Vehículos de motor, remolques y carrocerías } \\
\text { Refino de petróleo }\end{array}$ & $\begin{array}{r}322,323 \\
30 \\
29 \\
341-343,345 \\
232\end{array}$ \\
\hline $\begin{array}{l}\text { Media-alta } \\
\text { tecnología }\end{array}$ & $\begin{array}{l}\text { Productos farmacéuticos } \\
\text { Material eléctrico básico } \\
\text { Productos de tabaco } \\
\text { Productos químicos } \\
\text { Partes y accesorios de vehículos } \\
\text { Productos diversos } \\
\text { Celulosa y otras pastas para la fabricación de } \\
\text { papel }\end{array}$ & $\begin{array}{r}245 \\
321 \\
16 \\
241-244,246-249 \\
344 \\
369 \\
211\end{array}$ \\
\hline $\begin{array}{l}\text { Media-baja } \\
\text { tecnología }\end{array}$ & $\begin{array}{l}\text { Productos siderúrgicos } \\
\text { Caucho y plásticos } \\
\text { Productos de metal } \\
\text { Metalurgia de metales no ferrosos y fundición } \\
\text { Papel, embalajes y artefactos de papel } \\
\text { Productos minerales no metálicos } \\
\text { Pieles, artículos de cuero, artículos de viaje y } \\
\text { calzado }\end{array}$ & $\begin{array}{r}271-273 \\
25 \\
28 \\
274,275 \\
212-214 \\
26 \\
19\end{array}$ \\
\hline Baja tecnología & $\begin{array}{l}\text { Productos textiles } \\
\text { Productos alimenticios } \\
\text { Artículos de mobiliario } \\
\text { Industrias extractivas } \\
\text { Fabricación de prendas de vestir y accesorios } \\
\text { Productos de madera } \\
\text { Edición, artes gráficas y reproducción de } \\
\text { soportes grabados } \\
\text { Bebidas } \\
\text { Coque, alcohol y elaboración de combustibles } \\
\text { nucleares }\end{array}$ & $\begin{array}{r}17 \\
151-158 \\
361 \\
10,11,13,14 \\
18 \\
20 \\
22 \\
159 \\
231,233,234\end{array}$ \\
\hline
\end{tabular}

*Clasificación Nacional de Actividades Económicas

Fuentes: Elaboración propia a partir de IBGE. 